\title{
The small vesicular culprits: the investigation of extracellular vesicles as new targets for cancer treatment
}

\author{
Fumihiko Urabe ${ }^{1,2}$, Nobuyoshi Kosaka ${ }^{1 *}$, Yusuke Yoshioka ${ }^{1}$, Shin Egawa ${ }^{2}$ and Takahiro Ochiya ${ }^{1 *}$
}

\begin{abstract}
Extracellular vesicles (EVs) are membranous vesicles released from almost all type of cells including cancer cells. EVs transfer their components, such as microRNAs (miRNAs), messenger RNAs, lipids and proteins, from one cell to another, affecting the target cells. Emerging evidence suggests that reciprocal interactions between cancer cells and the cells in their microenvironment via EVs drive disease progression and therapy resistance. Therefore, understanding the roles of EVs in cancer biology will provide us with new opportunities to treat patients. EVs are also useful for monitoring disease processes. EVs have been found in many kinds of biological fluids such as blood, urine, saliva and semen. Because of their accessibility, EVs offer ease of collection with minimal discomfort to patients and are preferred for serial collection. In addition, they reflect and carry dynamic changes in disease, allowing us to access crucial molecular information about the disease status. Therefore, EVs hold great possibility as clinically useful biomarkers to provide multiple non-invasive snapshots of primary and metastatic tumors. In this review, we summarize current knowledge of miRNAs in EVs in cancer biology and as biomarkers. Furthermore, we discuss the potential of miRNAs in EVs for clinical application.
\end{abstract}

Keywords: Extracellular vesicles, miRNA, Clinical application

\section{Introduction}

Intercellular communication plays an essential role in multicellular organisms and can be mediated through direct cell-cell contact or through the transfer of secretory molecules. Recent studies have shown that as a new intercellular communication mechanism, small lipid bilayer vesicles, termed extracellular vesicles (EVs), play key roles in cancer progression and have great potential in clinical applications.

EVs are heterogeneous populations of vesicles that are secreted by almost all types of cells [1]. EVs include exosomes, microvesicles and apoptotic bodies, and these subgroups are categorized according to their origin, size and properties [2] (Fig. 1). Exosomes are small EVs (approximately $100 \mathrm{~nm}$ ) and are derived from the

\footnotetext{
*Correspondence: nkosaka@ncc.go.jp; tochiya@ncc.go.jp

${ }^{1}$ Division of Molecular and Cellular Medicine, National Cancer Center

Research Institute, 5-1-1 Tsukiji, Chuo-ku, Tokyo 104-0045, Japan

Full list of author information is available at the end of the article
}

intra-cellular endosomal compartment. Exosomes are initially formed by a process of inward budding into early endosomes to form multivesicular bodies (MVBs). These MVBs fuse with the limiting plasma membrane to release exosomes into the extracellular space $[3,4]$. As exosomal markers, members of the tetraspanin family (CD9, CD63 and CD81), members of the endosomal-sorting complex required for transport (ESCRT) complex (TSG101, Alix), heat shock proteins (Hsp60, Hsp70, Hsp90) and Rab proteins $(\mathrm{Rab} 27 \mathrm{~A} / \mathrm{B})$ are recognized $[5,6]$. Microvesicles are larger than exosomes $(100-1000 \mathrm{~nm})$ and are directly shed or bud from the plasma membrane in response to stimulation [7]. Microvesicles have been reported to be enriched in phosphatidylserine and have several lipids components [8]. Apoptotic bodies are several micrometers in diameter $(800-5000 \mathrm{~nm})$ and are released from the cell undergoing programmed cell death. Despite being classified by the origin of these vesicles, we must consider that current techniques cannot clearly distinguish each type of EV separately [9]. To avoid confusion, 


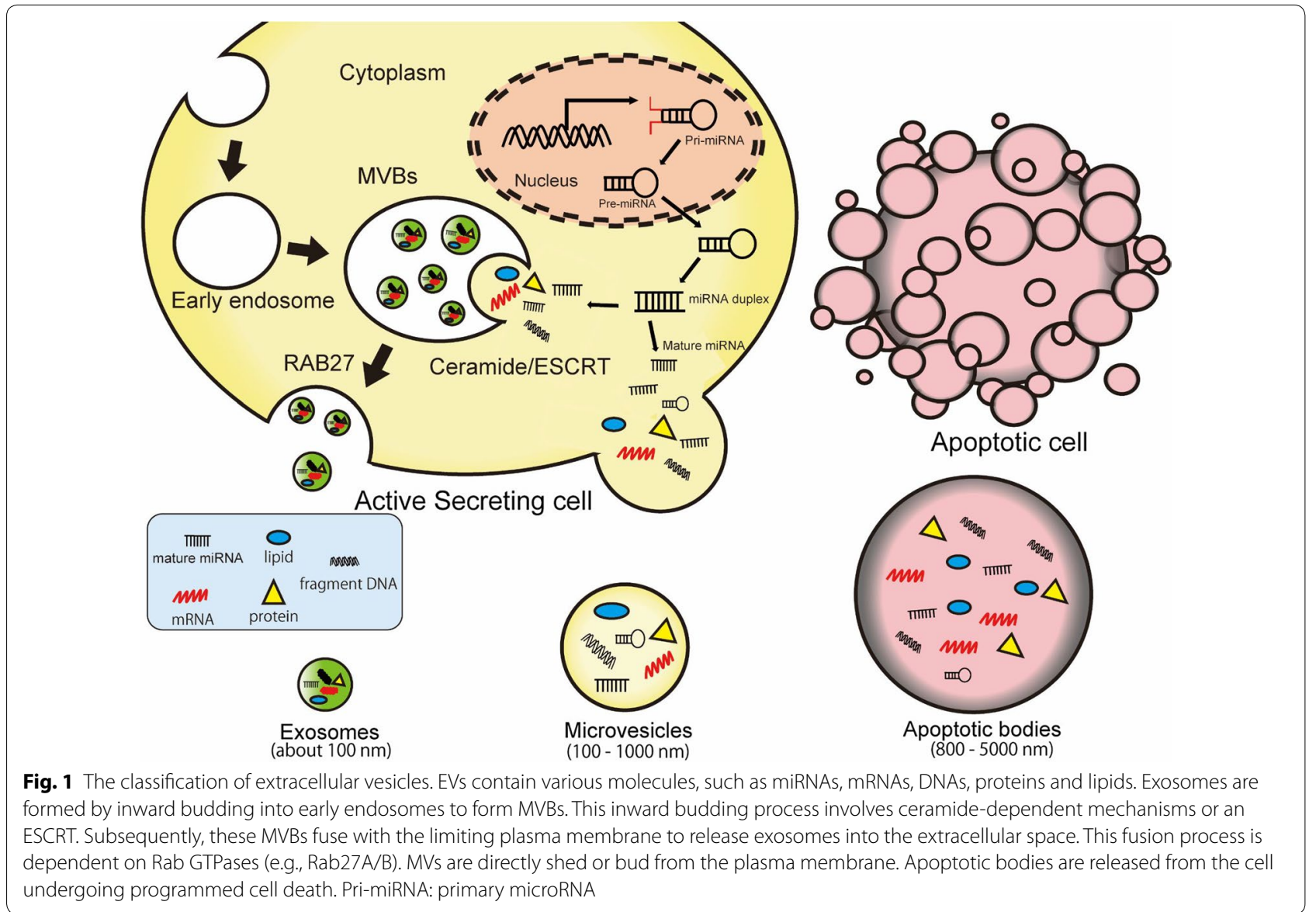

in this review, we use EVs as a general term for all types of vesicles in the extracellular milieu, according to the recommendation of the International Society for Extracellular Vesicles (ISEV) [10].

Although EVs have long been considered as disposal vehicles to eliminate unwanted proteins and biomolecules [11], in 2007, Valadi et al. identified miRNA as well as mRNA inside EVs and showed the potential functionality of these nucleic acids in recipient cells [12]. miRNAs are small single-stranded non-coding RNAs that negatively regulate gene expression by binding to the $3^{\prime}$ untranslated region ( $3^{\prime}$ UTR) of mRNA, leading to mRNA degradation or the inhibition of translation [13]. Through this mechanism, miRNAs are involved in the progression of various diseases including cancer [14]. In 2010, three independent groups published that miRNAs in EVs can be transferred to immune cells [15], cancer cells [16], and endothelial cells [17] and have functions within these cells. Subsequently, many researchers started to focus on miRNAs in EVs, and accumulating evidence has demonstrated that EVs transfer miRNAs from one cell to another and that their components have an effect on cancer progression $[18,19]$.
In this review, we summarize the potential of miRNAs in EVs in clinical applications. First, we describe the contribution of miRNAs in EVs to cancer biology. Next, we discuss the possibility of EV-targeting therapy. In the second part, we provide an overview of the utility of miRNAs in EVs as biomarkers of several major cancers. We focus on the problem associated with the present tumor biomarkers and discuss the possible uses of miRNAs in EVs as diagnostic and prognostic biomarkers.

\section{The role of EVs in the cancer microenvironment Induction of angiogenesis and endothelial cell permeability}

Due to the hypoxic condition in tumors, angiogenesis, the formation of new blood vessels from an existing vasculature, is crucial for cancer cells [20]. Abnormal tumor angiogenesis is widely accepted as the major problem in cancer due to its contribution to cancer proliferation and therapy resistance. In addition, tumor vessels exhibit a high permeability, increasing metastatic dissemination $[21,22]$. Endothelial cells are one origin of tumor vessels [23], and accumulating evidence has shown that cancer cell communication with endothelial cells via miRNAs 
in EVs is associated with angiogenic activity in tumors [24-27].

For example, Zhuang et al. reported that miR-9-5p in EVs from murine cancer cells was delivered into endothelial cells and promoted the migration of endothelial cells and angiogenesis. They found that secreted miR9-5p reduced levels of suppressor of cytokine signaling 5 (SOCS5) and activated the JAK-STAT pathway in endothelial cells, leading to angiogenesis in tumors [24]. miR-210 is described as the major hypoxamir [28], inducing angiogenesis in endothelial cells and targeting Ephrin-A3 [29]. Several reports have shown that miR210-3p in EVs also contributes to tumor angiogenesis [25, 26]. Kosaka et al. showed that the neutral sphingomyelinase 2 (nSMase2) regulates EV-associated miR-210-3p secretion and promotes angiogenesis, which affects the capacity for metastasis [25]. Cui et al. reported that tissue inhibitor of metalloprotease-1 (TIMP-1) lead to an accumulation of miR-210-3p in EVs via activation of the $\mathrm{PI} 3 \mathrm{~K} / \mathrm{AKT} / \mathrm{HIF}-1 / \mathrm{miR}-210$ signaling cascade under normoxic conditions [26]. In another study, Hsu et al. have shown that miR-23a-3p in EVs from hypoxic lung cancer cell increase not only angiogenesis but also vascular permeability. EVs containing miR-23a-3p directly suppress prolyl hydroxylase 1 and 2, activating the expression of hypoxia-inducible factor- $1 \alpha$ in endothelial cells, which results in angiogenesis induction. miR-23a-3p also inhibits the tight junction protein zonula occludens-1 (ZO-1), which has been reported to play a central regulatory role in controlling angiogenesis barrier formation [30] and thereby increasing vascular permeability [27].

Tumor-derived EVs affect endothelial cells in distant microenvironments to form a metastatic site. The bloodbrain barrier (BBB) consists of endothelial cells and surrounding cells, and it normally serves as a defensive barrier. BBB destruction is one of the key events during brain metastasis [31], and previous reports have shown that miRNAs in cancer-derived EVs increase endothelial cell permeability and induce brain metastasis. Zhou et al. showed that metastatic breast cancer-derived EVs contain miR-105-5p, which targets the tight junction protein $\mathrm{ZO}-1$, thereby inducing endothelial cell permeability and brain metastasis [32]. In another study, Tominaga et al. showed that EVs derived from a brain metastatic breast cancer cell line, which contains miR-181c-5p, induce destruction of the BBB [33]. miR-181c-5p negatively regulates 3-phosphoinositide-dependent protein kinase-1 (PDPK1) and causes degradation of phosphorylated cofilin and severing of actin filaments [33]. Thus, cancer-derived EVs regulate the endothelial cell phenotype, thereby contributing to cancer progression and metastasis. From a clinical perspective, sunitinib and sorafenib, which are popular molecular target drugs, inhibit the effect on vascularization by targeting vascular endothelial growth factor receptors (VEGFRs) or platelet-derived growth factor receptors (PDGFRs) [34]. However, previous studies have reported that these drugs are not successful in establishing a beneficial effect in advanced lung and breast cancer $[35,36]$. As previously mentioned, the transfer of miRNAs in EVs derived from lung and breast cancer cells to endothelial cells activate different pathways to regulate angiogenesis or vascular permeability, which could be targeted by vascularization-inhibiting molecular drugs [24-27]. Therefore, intercellular transfer of EVs could be a new therapeutic target, especially for lung and breast cancer.

\section{Crosstalk between cancer cells and stromal fibroblasts}

Cancer-associated fibroblasts (CAFs) are the major component of the tumor microenvironment, and CAFs have been reported to play a key role in malignant progression [37].

The mechanism responsible for $\mathrm{CAF}$ induction remains controversial, but recent studies have shown that TGF- $\beta$ is partially responsible for activating CAFs $[38,39]$. In addition, EVs derived from cancer cells also induce CaFlike phenotypes in resident fibroblasts. Pang et al. showed that EVs derived from pancreatic cancer containing miR155-5p, which targets TP53INP1, result in the proliferation and activation of normal fibroblasts [40].

In contrast, CAFs also provide a benefit for cancer progression. Yeung et al. demonstrated that CAFs and cancer-associated adipocytes secrete higher levels of miR-21-5p in EVs than in those from ovarian cancer cells, by using next-generation sequencing technology. In that study, they also revealed that miR-21-5p suppresses ovarian cancer apoptosis and confers chemoresistance by binding to AFAP1 [41]. Donnarumma et al. showed that in breast cancer, CAF-derived EVs contain three miRNAs (miR-21-5p, -378e, 143-3p) that induce stemness and epithelial-mesenchymal transition (EMT) of breast cancer cells, regulating the development of an aggressive cancer phenotype [42].

In another study, Baroni et al. observed cross-talk between cancer cells and fibroblasts. miR-9-5p, which is upregulated in triple-negative breast cancer (TNBC)derived EVs, induces CAF-like properties in human breast fibroblasts. Moreover, fibroblasts activated by miR-9-5p alter the tumor behavior, modulating genes involved in cell motility and extracellular matrix (ECM) modeling [43]. Thus, interactions between cancer cells and CAFs via EVs promote cancer proliferation.

In addition, several reports have revealed that cancerderived miRNAs in EVs contribute to cancer progression through remodeling the fibroblasts within the distant site. Rana et al. found that cancer-associated miR-494 
and miR-542-3p in EVs are transferred to lymph node stromal cells and lung fibroblasts, targeting cadherin-17 and upregulating matrix metalloprotease [44]. Fong et al. revealed that breast cancer cell-derived miR-122-5p in EVs suppresses glucose intake in astrocytes and lung fibroblasts by inhibiting pyruvate kinase. This increased glucose utilization and promotion of circulating tumor cell colonization favors brain and lung metastasis [45]. Fibroblast remodeling at distant sites is one of the major components of the developing premetastatic niche [46], and these studies indicate an additional contributory role of miRNAs in EVs.

\section{Modulation of the immune system}

Escape from immune-mediated tumor destruction has been recognized as a hallmark of cancer [47]. Zitvogel et al. and Wolfers et al. were the first researchers to show the relationship between EVs derived from cancer cells and the immune system, and many studies have since confirmed this relationship [48, 49]. In the tumor microenvironment, immune cells, such as macrophages, natural killer cells, $\mathrm{T}$ lymphocytes and B lymphocytes, interact with tumor cells and regulate tumorigenesis and progression. It has been acknowledged that tumor progression is partly related to the extent of immune dysfunction, and emerging data indicate that EVs are a novel contributor to the immune modulation. EVs derived from cancer mostly have immunosuppressive effects that support tumor progression and metastasis. For instance, Kim et al. have shown that EVs from oral cancer patient sera contain FasL and induce apoptosis in Jurkat and CD8 ${ }^{+}$ $\mathrm{T}$ cell [50]. Myeloid-derived-suppressor cells (MDSCs) have been identified as a population of immature myeloid cells with the ability to suppress $\mathrm{T}$ cell activation, contributing to cancer proliferation [51]. Chalmin et al. found that heat shock protein 72 (Hsp72) expressed on tumor-derived EVs triggers STAT3 activation in MDSCs through toll-like receptor 2, inducing their immunosuppressive activity [52].

In addition, cancer cell-derived EVs recruit immune cells to enhance tumor invasion and dissemination. Fabbri et al. have revealed that lung cancer-derived EVs containing miR-21-5p and miR-29a-3p, which bind as ligands to the toll-like receptor (TLR) family (murine TLR7 and human TLR8) in surrounding tumor-associated macrophages (TAMs), trigger NF- $\mathrm{KB}$-mediated pro-inflammatory cytokine production and support the progression of cancer [53]. In another study, Ying et al. have found that miR-222-3p in EVs derived from epithelial ovarian cancer (EOC) cells shift macrophages toward a tumor-supportive TAM-like phenotype [54]. Regarding the immune escape system, many types of cancer cells upregulate the expression of programmed death-1 ligand (PD-L1), which plays an important role in blocking the immune system by binding to PD-1 expressed on the surface of $\mathrm{T}$ cells and induces programmed death in activated $T$ cells [55]. Several studies have revealed that miRNA indirectly regulates the expression of PD-L1 in cancer cells. Fujita et al. demonstrated that miR-197-3p indirectly regulates PD-L1 expression via the miR-197/ CKS1B/STAT3-mediated PD-L1 network [56]. Chen et al. showed that the expression of PD-L1 in lung cancer is regulated by the miR-200/ZEB1 axis and the subsequently suppresses $\mathrm{CD} 8^{+} \mathrm{T}$ cells in the tumor environment [57]. In 2016, Kataoka et al. reported that disruption of the PD-L1 3'-untranslated region (UTR) is associated with cancer cells aberrantly expressing PD-L1 [58]. The $3^{\prime}$ UTR is the site bound by miRNAs, suggesting the possibility that miRNAs may directly mediate the expression of PD-L1. In addition, Haderk et al. recently reported that noncoding Y RNA hY4 in EVs derived from chronic lymphocytic leukemia (CLL) modulate PD-L1 expression in monocytes [59]. Although confirmation is still needed, these results support the presence of miRNAs packaged in EVs to regulate PD-L1 expression.

\section{Regulation of cancer cell proliferation and drug resistance}

EVs derived from cancer cells or microenvironmental cells affect cancer cell proliferation and drug resistance and regulate tumor progression during various phases.

First, during tumor initiation, there is competition between cancer cells and the surrounding normal epithelial cells [60]. Kosaka et al. demonstrated that normal epithelial prostate cells secrete EVs containing miR-143-3p, suppressing the proliferation of prostate cancer cells [16]. miR-143-3p in EVs derived from normal epithelial prostate cells negatively regulates KRAS and ERK5, repressing the proliferation of cancer proliferation. Normal epithelial cells derived EVs contribute to the maintenance of homeostasis and prevent cancer initiation; however, once the cancer cells overcome the suppression, the primary tumor starts to progress.

Primary tumors consist of heterogeneous cells with varying proliferative, invasive and metastatic abilities. Hence, through the intra-tumor transfer of EVs, tumor cells can collaborate to drive tumor progression. Le et al. showed that the transfer of miR-200 family from metastatic breast cancer cells to poorly metastatic breast cancer cells promote mesenchymal-to-epithelial transition (MET) [61]. Although metastasis involves multiple steps, MET is a crucial step during the development of metastasis at distant sites. In a xenograft model, they revealed that miR-200 miRNAs in EVs from metastatic cells promoted metastasis in otherwise weakly metastatic cells, and demonstrated that the metastatic capacity could be transferred via the uptake of EVs. In another study, Singh 
et al. reported that the transfer of miR-10b-5p in EVs from metastatic breast cancer cells promotes the invasive capacity of non-malignant cells by targeting HOXD10 [62]. Although their findings did not directly indicate that less invasive cancer cells became more invasive via the transfer of EVs from metastatic cancer cells, their results suggest that cancer-associated miRNAs in EVs can promote adjacent cells and lead to outcomes favoring tumor proliferation.

For patients with advanced-stage cancer, chemotherapy and targeted drugs are the main treatment strategies; however, their effectiveness does not last for long periods due to resistance [63]. Several studies have shown that EVs play a role as a noteworthy vehicle of the dissemination of cancer drug resistance. Indeed, horizontal transfer of miRNA via EVs is one of the main mechanisms leading to drug resistance. Chen et al. revealed that drug-resistant breast cancer cells secrete several miRNAs (miR-30a-5p, miR-100-5p and miR-222-3p) that are enriched in EVs, reducing the drug sensitivity of drug-sensitive cancer cells [64]. Recently, Wei et al. indicated that miR-222-3p, which is secreted by drug-resistant non-small-cell lung cancer (NSCLC) cells in EVs, is transferred and promotes gemcitabine resistance in sensitive cells by targeting suppressor of cytokine signaling 3 (SOCS3) [65]. Challagundla et al. revealed that a unique cross-talk between neuroblastoma cells and human monocytes through miR-21-5p and miR-155-5p in EVs contributes to the development of drug resistance. NBL cells secrete miR-21-5p in EVs transferred to monocytes, activating the NF- $\mathrm{KB}$ pathway and upregulating miR-155-5p in monocytes. In return, activated monocytes secrete miR-155-5p in EVs transferred to NBL cells, targeting TERF1 and providing drug resistance [66].

EVs are also related to long-term recurrence. Bone marrow is one of the major homing organs for disseminated breast cancer cells. Even 10-20 years after resection of the primary site, breast cancer patients often develop a recurrence, especially in the bone marrow [67], which indicates that breast cancer cells spread and survive for a long time in a dormant state. Ono et al. revealed that the mechanism responsible for the maintenance of dormancy in bone marrow includes the transfer of miRNA in EVs secreted by bone marrow mesenchymal stem cells (BM-MSC) [68]. miR-23b-3p in BM-MSC-derived EVs contribute to the dormant state of breast cancer cells by downregulating a target gene, myristoylated alanine-rich C-kinase substrate (MARCKS), which encodes a protein that promotes cell cycling a motility. Therefore, cancer surrounding noncancerous BM-MSCs plays an important role in inducing breast cancer cells dormancy and future recurrence.
As summarized above, EVs have various effects on cells in the cancer microenvironment and on cancer cells themselves, participating in the various timing features of tumor progression. Thus, it is crucial to understand the molecular mechanisms underlying cancer progression by EVs, and then we can consider tactics to defeat cancer by targeting EVs. In the next section, therapeutic strategies by EV targeting are discussed.

\section{EV-targeting therapeutic strategies}

As we have shown, intercellular communication via EVs contributes to tumor progression through the transfer of their cargo (Fig. 2; Table 1). In addition, the pathways that are activated by the transfer of miRNAs in EVs mostly differ from those targeted by modern drugs, such as chemotherapy or molecular targeting drugs. Therefore, a reduction of cancer-derived EVs transfer will provide additional therapeutic value for inhibiting cancer proliferation and dissemination. Three potential therapeutic strategies, inhibition of EV production, elimination of circulating EVs and disruption of the absorption of EVs, have been proposed [18] (Fig. 3). In this section, we summarize these strategies and discuss their potential clinical applications.

Several articles have described the effectiveness of inhibiting EV production in vitro and in vivo. In 2013, Kosaka et al. revealed that knockdown of nSMase2, which is required for the synthesis of ceramide, EV secretion and miR-210-3p transfer, is inhibited, and angiogenesis and metastasis in a xenograft mouse model are suppressed [25]. In another study, Yokoi et al. reported that knockdown of nSMase2 suppresses peritoneal dissemination in ovarian cancer by inhibiting EV production [69]. Until now, other molecules related to EV production, such as RAB27A, RAB27B and TSG101, have also been reported to be effective for inhibiting cancer-derived EV production [70, 71]. Inhibition of EV production will provide a chance to suppress intercellular communication, and therefore this strategy has great potential for the treatment of cancer. However, these genes have key roles in multiple cell biological events, and therefore their downregulation in normal cells would have adverse effects on normal cell functioning [18]. Indeed, it has been reported that nSMase 2 is expressed in normal neural cells [72]. In addition, the downregulation of these genes may not have the same inhibitory effects on EV secretion between cancer types. Phuyal et al. have reported that inhibition of nSMase2 does not inhibit EV secretion in a prostate cancer cell line [73]. Therefore, to identify the genes related to cancer type-specific EV production is a future challenge.

In 2012, Marleau et al. described a therapeutic strategy for the removal of circulating EVs. In their study, they 


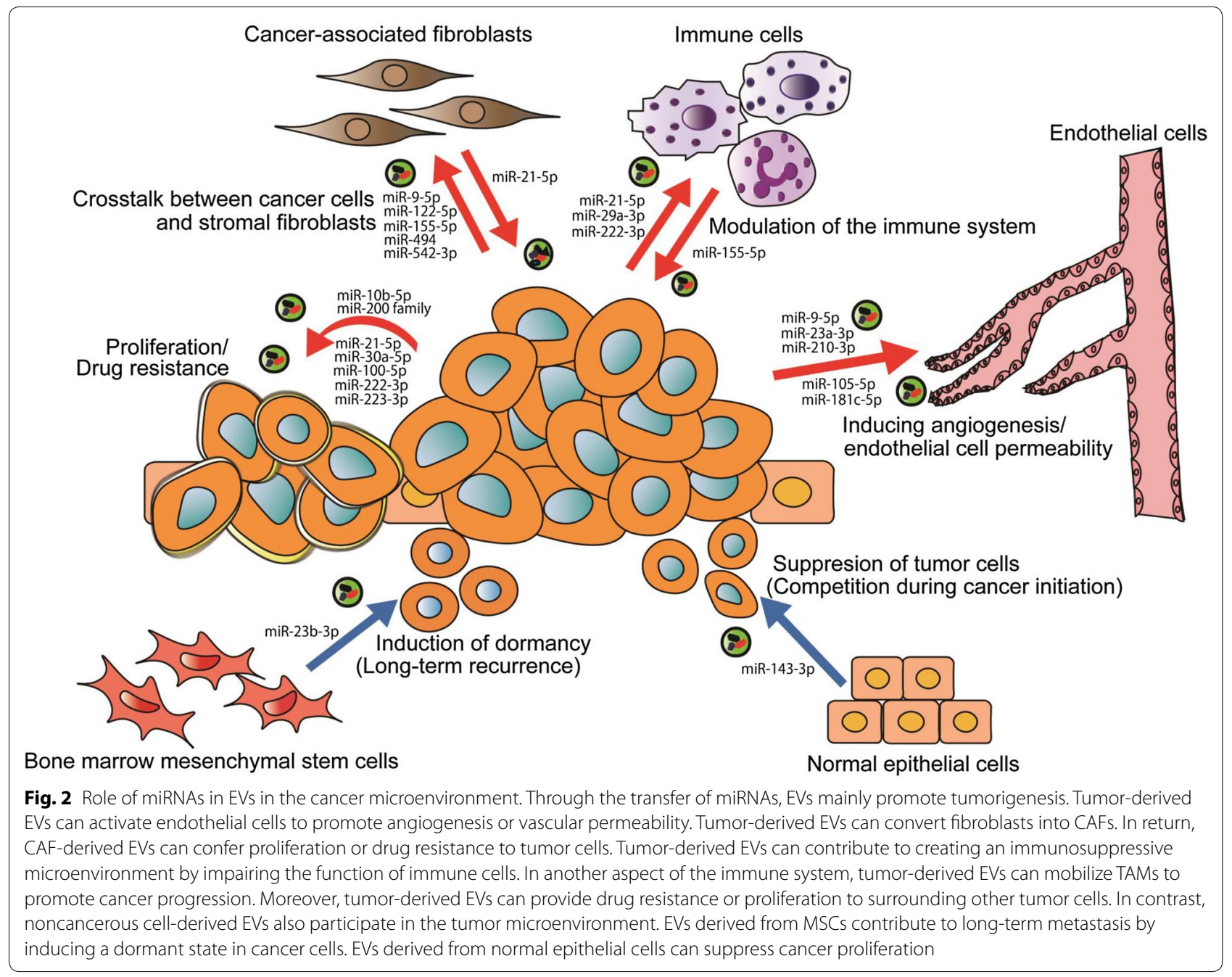

developed the hemofiltration system, which can specifically capture circulating cancer cell-derived HER2-positive-EVs [74]. HER2-expressing EVs have been shown to interfere with therapy and are associated with cancer progression [75]; therefore, selectively eliminating HER2-expressing EVs could be a new strategy to treat breast cancer. In 2012, Peinado et al. showed that circulating EVs contribute to cancer metastasis by establishing a premetastatic niche, and they suggested a therapeutic strategy [76]. Thus, it is natural to focus on the possibility that targeting the circulating EVs from cancer cells could be a strategy for preventing cancer metastasis. Recently, Nishida-Aoki et al. revealed a new idea for eliminating EVs [77]. They showed that in a human breast cancer xenograft mouse model, administration of antibodies against human-specific CD9 and CD63, which are enriched on the surface of EVs, significantly decreased metastasis, although no obvious effects on primary site growth were observed. In that study, EVs tagged by
anti-CD9 and CD63 were internalized by macrophages via phagocytosis before they could promote cancer progression. In humans, anti-CD9 and CD63 antibodies cannot selectively attach to cancer-derived EVs, so further investigations are needed. However, if we can identify the location of the cancer-specific molecules on EVs in more detail, circulating EV elimination, via using their antibodies, could potentially be applied to treat patients. Therefore, that study suggested a new novel treatment strategy for cancer.

Inhibition of EV internalization will also provide new therapeutic strategies. Christianson et al. showed that heparan sulfate proteoglycans (HSPGs) serve as receptors of EVs derived from glioblastoma (GBM) [78]. Heparin, which is an HS mimetic, dose-dependently inhibits EV uptake and suppresses EV-dependent cell migration in GBM. Several other molecules related to EV internalization have also been reported [79-81]. However, the mechanism responsible for EV internalization is 


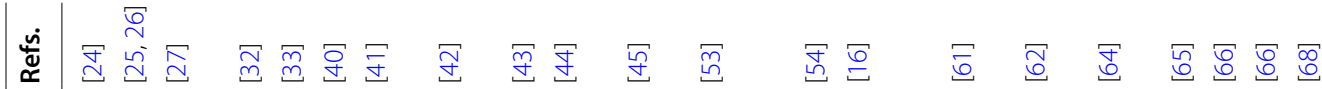

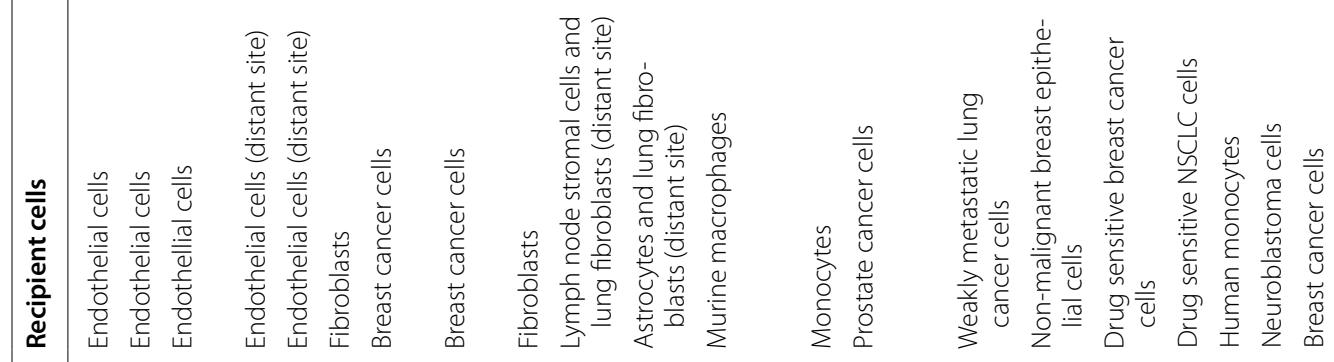

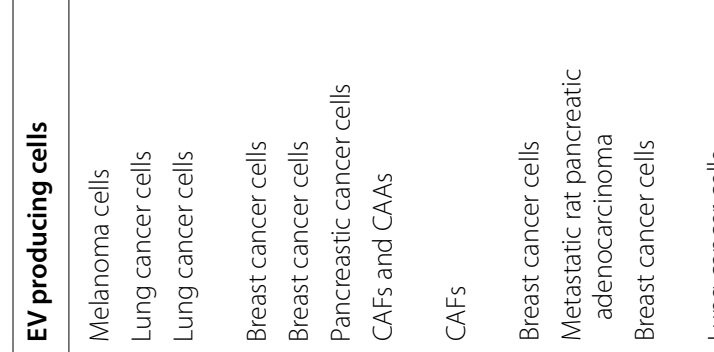

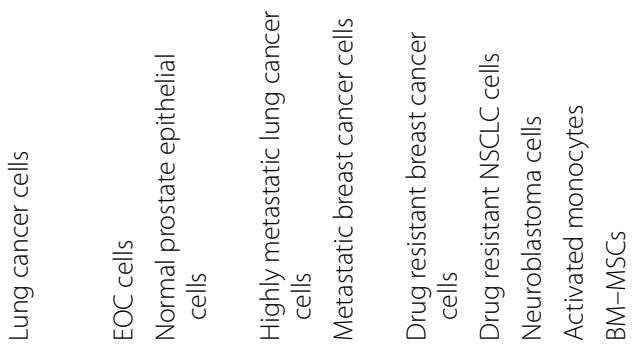
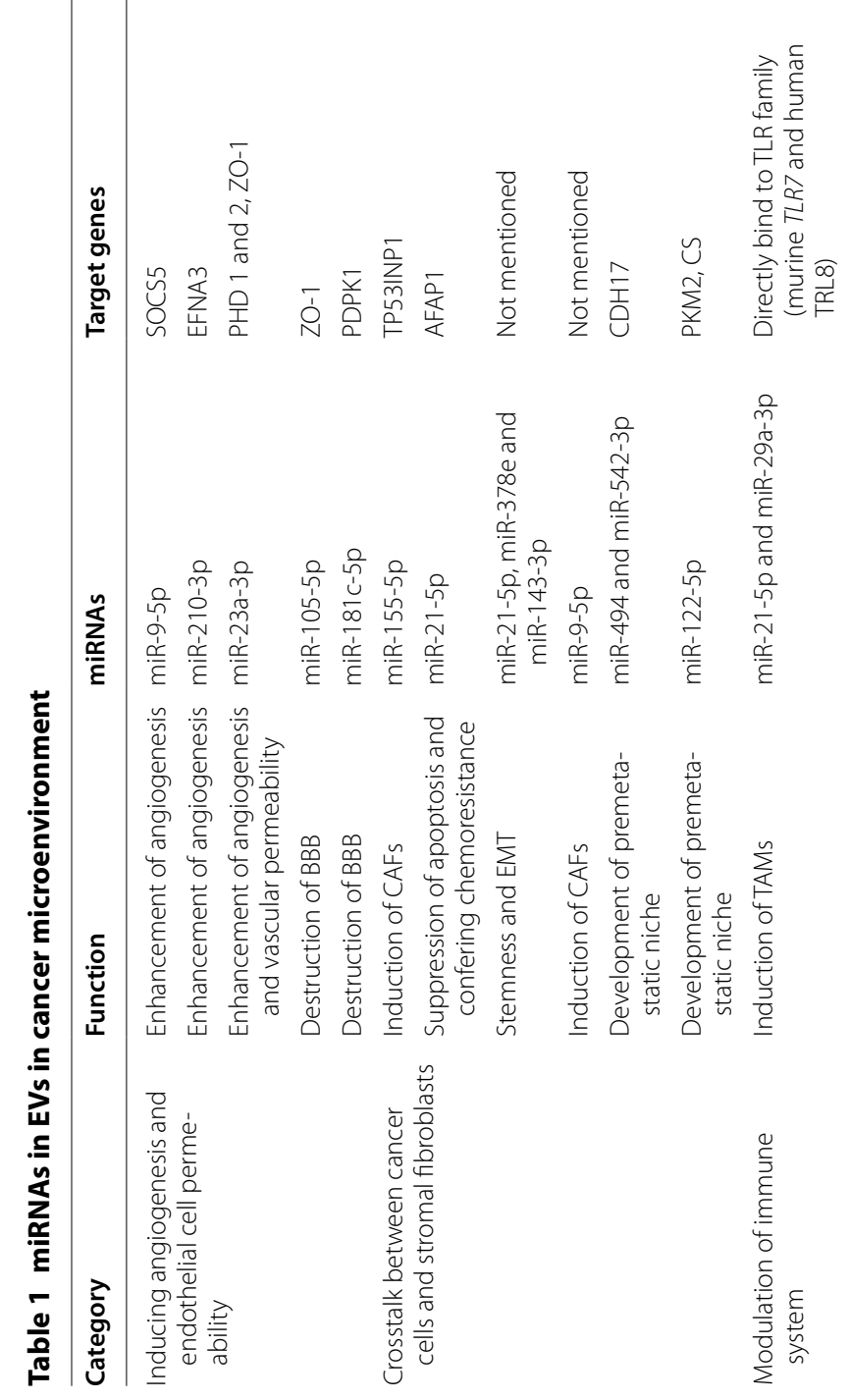

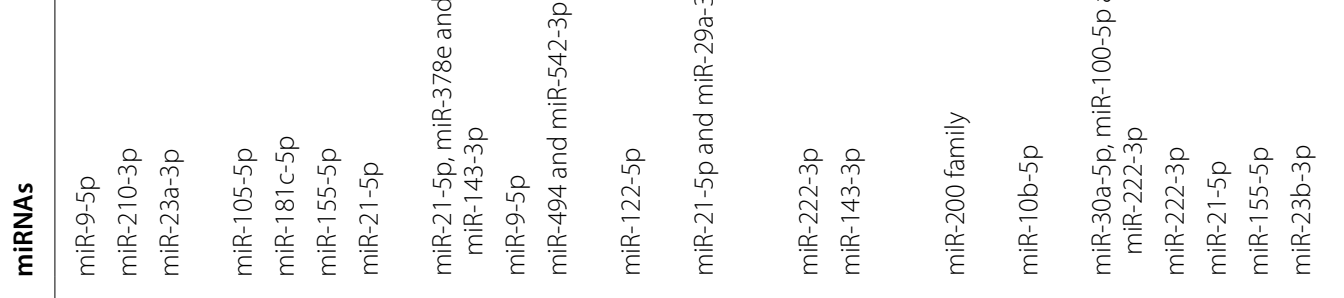

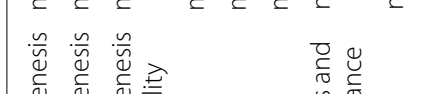

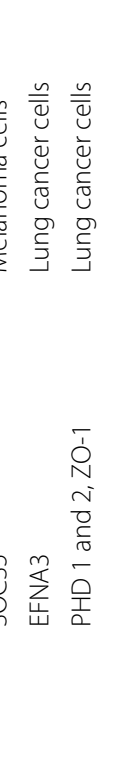

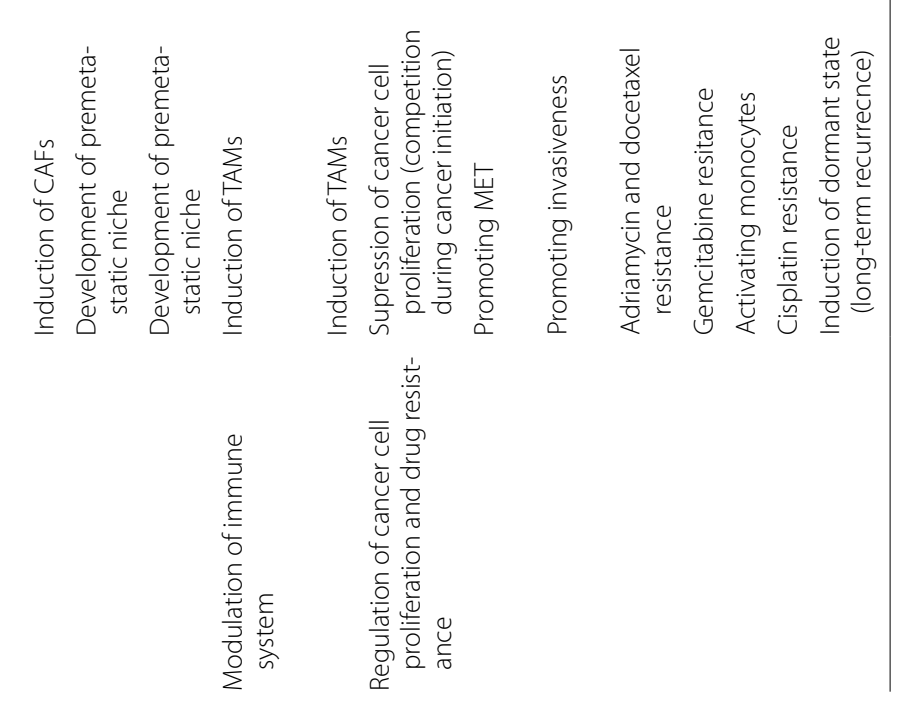




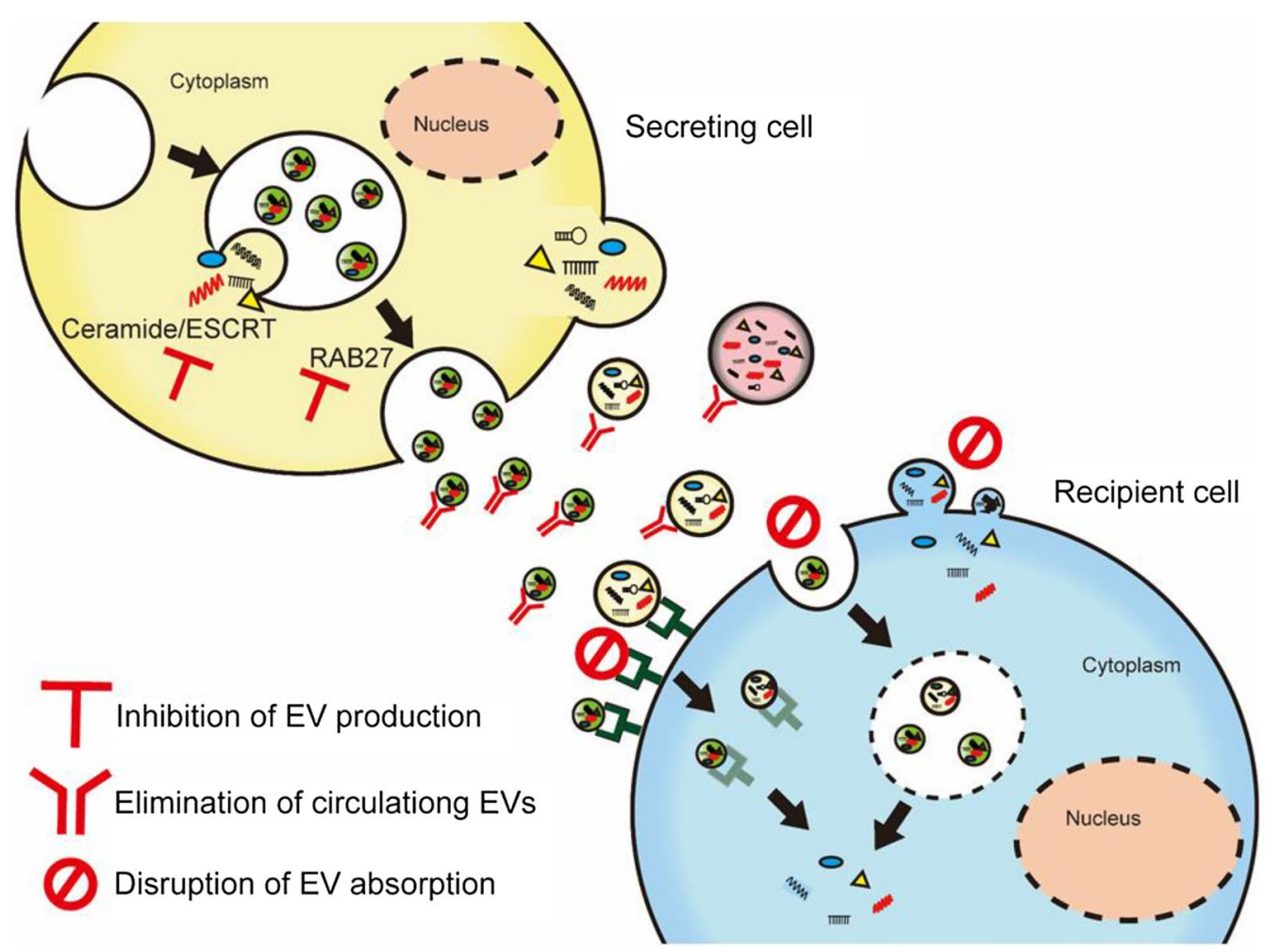

Fig. 3 Schematic of EV-targeting therapy. Intercellular transfer of the EV cargo contributes to cancer development, so reducing EV transfer will provide new therapeutic strategies. Inhibition of EV production, elimination of circulating EVs and disruption of EV absorption will be main strategies

quite complex and more obscure than the secretion mechanism. Unfortunately, no study has demonstrated an effect of inhibiting EV internalization in vivo. One explanation for this deficit is the lack of detailed knowledge about the cancer cell-specific EV uptake pathway. Like the other two strategies, avoiding damage to normal cell homeostasis should be a priority during therapeutic development, and thus the identification of cancerspecific EV uptake pathways is crucial. In 2016, Kowal et al. reported that different EV fractions have different EV protein markers [82], and they suggested that different EV fractions have different molecular and biological properties. Furthermore, in 2017, Tkach et al. reported that immature dendritic cells secrete two different EV subpopulations, namely, small EVs and large EVs, which have different effects on $\mathrm{T}$ helper cell [83]. Therefore, the identification of EV subpopulations with more oncogenic cargo that affect recipient cells and their specific internalization pathways may be the most effective strategies.

As we have shown, inhibition of EV transfer suppresses tumor development and represents a new therapeutic strategy. Although many challenges remain, the astonishing advances in the EV field provide promise that they will be overcome. In the future, targeting EV therapy would be considered a standard treatment, such as surgery, radiotherapy and chemotherapy.

\section{EV-associated miRNAs as biomarkers in cancer}

Approximately 10 years ago, the existence of miRNA in EVs and the presence of tumor-derived EVs in the peripheral circulation were reported [12, 84]. Since then, many studies have supported the possibility of miRNAs in EVs as cancer biomarkers.

Compared with conventional tissue biopsy, EV-based liquid biopsy has several merits. First, almost all cells secrete EVs, which can be found in many kinds of body fluids such as blood [85], urine [86], saliva [87] and semen [88]. Due to their easy accessibility, EVs offer ease of collection with minimal discomfort to the patients and are preferred for serial collections. In addition, although the small size of a tissue biopsy may not reflect the total genetic heterogeneity within the disease, EVs shed from heterogeneous cancers reflect the dynamic changes that occur during disease and allow us to access crucial molecular information about the status of diseases. Furthermore, miRNAs in EVs are more suitable for the development of biomarkers than other circulating miRNAs because EVs are small lipid bilayer vesicles, and their cargo is protected from ribonucleases [3]. Therefore, EVs 
hold greater possibilities as clinically useful biomarkers to provide multiple non-invasive snapshots of primary and metastatic tumors. In this section, we describe the limitations of current biomarkers and summarize recent clinical sample-based studies of diagnostic and prognostic biomarkers in the six major cancers.

\section{Lung cancer}

Lung cancer is the most common and the leading cause of cancer-related death in the United States [89]. NSCLC accounts for approximately $80 \%$ of all cases of lung cancer, and NSCLC has a poor 5-year survival rate due to the delay in detection of the disease [90]. There are no validated procedures to detect early-stage NSCLC other than low-dose helical computed tomography scanning [91], and therefore valuable biomarkers are required. Several reports have demonstrated the usefulness of miRNAs in EVs as diagnostic or prognostic biomarkers for NSCLC. In 2013, Cazzoli et al. used wide-range miRNA analysis to select candidate miRNAs in plasma-derived EVs from 10 patients with NSCLC, 10 patients with lung granuloma and 10 healthy smokers. Subsequently, selected miRNAs were validated in a larger independent group of samples (105 NSCLC patients, 50 lung granuloma patients and 25 healthy smokers). The result showed that the screening model (including miR-378a-3p, miR-379-5p, miR-139-5p and miR-200-5p) distinguishes between patients with any kind of nodules and control smokers, with an area under the receiver operating characteristic curve (AUC) of 0.908 , sensitivity of $97.5 \%$ and specificity of $72.0 \%$. The diagnostic model (including miR-151-5p, miR-30a-3p, miR-200b-5p, miR-629-5p, miR-100-5p and miR-154-3p) discriminates between NSCLC and granuloma, with an AUC of 0.76 , sensitivity of $96 \%$ and specificity of $60 \%$ [92].

In 2017, Jin et al. reported highly sensitive noninvasive biomarkers for early detection of NSCLC. They performed RNA-sequence (RNA-seq) to identify candidates and validate adenocarcinoma and squamous cell carcinoma (SCC)-specific miRNAs from 46 stage I NSCLC patients and 42 healthy individuals. They detected diagnostic biomarkers for NSCLC (let-7b-5p, miR-21-5p, miR-24-3p and miR-486-5p), adenocarcinoma (miR181-5p, miR-30a-3p, miR-30e-3p and miR-361-5p) and SCC (miR-10b-5p, miR-15b-5p and miR-320b). Surprisingly, the diagnostic accuracy of combination miRNA panels exhibited an area under the curve (AUC) value of $0.899,0.936$, and 0.911 for the detection of NSCLC, adenocarcinoma, and SCC [93].

Despite the progression of NSCLC therapy, the prognosis for patients with NSCLS remains poor. Therefore, clarification of the prognostic biomarkers is required to improve the outcome of NSCLC patients. In 2017, Liu et al. found that miR-23b-3p, miR-10b-5p and miR-21-5p in plasma-derived EV are independent prognostic biomarkers for NSCLC. They selected candidate miRNAs using a qPCR-array panel and validated by qRT-PCR. Addition of the three miRNAs significantly improved the predictive accuracy for survival, with an increase in the time-dependent AUC from 0.88 to 0.91 [94]. Dejima et al. used microarray analysis to examine plasma from 3 NSCLC patients with recurrence after surgery, 3 patients without recurrence and 3 healthy volunteers. They then assessed the candidate miRNAs in a separate cohort of 195 NSCLC patients and 30 healthy individuals. The results showed that disease-free survival was significantly worse in the high miR-21-5p group and the high miR4257 group, respectively, suggesting that the expression of miR-21-5p and miR-4257 in EVs has potential as a predictive biomarker for recurrence after surgical resection [95].

\section{Colorectal cancer}

Colorectal cancer (CRC) is the third most common cancer and the second leading cause of cancer-related death in the United States [89]. The prognosis of CRC is dependent on the disease stage at diagnosis, with a 5-year survival rate of $90 \%$ when diagnosed in the early stage [96]. Colonoscopy is the authorized method for diagnosis, but its invasiveness and uncomfortableness inhibit medical examination. The serum markers CA199 and CEA are useful for detecting CRC, but with low sensitivity and specificity [97]. Therefore, reliable and non-invasive biomarkers are needed.

In 2014, Ogata-Kawata et al. reported the possibility of seven miRNAs (let-7a-5p, miR-1229-3p, miR-1246, miR150-5p, miR-21-5p, miR-223-3p and miR-23a-3p) in EVs as early diagnostic biomarkers for CRC. Compared with healthy controls, these miRNAs were significantly elevated in CRC patients [98]. In addition, they were significantly upregulated even in early-stage CRC patients and decreased after surgical resection. Recently, Wang et al. reported the potential of miR-125a-3p in plasma-derived EVs as a biomarker for early-stage colon cancer. They selected candidate miRNAs by small RNA sequencing and validated them in 50 early-stage CRC patients and 50 matched healthy volunteers. Although the diagnostic power of miR-125a-5p by itself was not very high (AUC: 0.6849 ), the multivariate model showed an increased diagnostic power in combination with CEA with an AUC of 0.855 , indicating that miR-125a-3p is an independent biomarker from CEA [99].

Despite surgical intervention and adjuvant therapy, recurrence is common in patients with CRC [100]. Several studies have shown that miRNAs in EVs could be potential biomarkers of recurrence in CRC. Matsumura 
et al. revealed that miR-19a-3p in EVs could be a prognostic biomarker for recurrence in CRC patients. They performed miRNA microarray analysis of EVs from patients with recurrence and with non-recurrence. They also performed microarray and CGH array analysis in $124 \mathrm{CRC}$ tissue samples. By comparing these results, they selected the miR-17-92a cluster as candidate miRNAs and validated them by qRT-PCR. Finally, they showed an association between the expression of miR-19a-3p in serum-derived EVs and a poorer prognosis [101]. In 2016, Liu et al. showed that the level of miR-4772-3p in EVs is significantly reduced in patients with stage II/III CRC patients with recurrence, with an AUC of 0.72, sensitivity of $78.6 \%$ and specificity of $77.1 \%$. In that study, RNA seq-based miRNA profiling methods were performed to select candidate miRNAs [102].

\section{Prostate cancer}

Prostate cancer $(\mathrm{PCa})$ is the most frequently diagnosed male tumor and the third leading cause of cancer-related death in males in the United States [89]. Prostate-specific antigen (PSA) is the gold standard biomarker to diagnose and monitor the response to treatment. However, PSA has a low specificity with a high false positivity in patients with benign prostatic hyperplasia (BPH) [103]. Therefore, new biomarkers are needed for the accurate diagnosis and stratification of patients with PCa.

Bryant et al. analyzed miRNAs in plasma-derived EVs from a cohort of $78 \mathrm{PCa}$ patients and 28 normal control individuals using a microarray panel of 742 miRNAs, finding a total of 12 differentially quantified miRNAs. Among these miRNAs, they confirmed an association of miR141-3p and miR-375 with metastatic PCa using serumderived EVs in a separate cohort by qRT-PCR [104]. miR-141-3p is one of the most common cancer-associated miRNAs, which is useful for the diagnosis of prostate cancer and prediction of metastasis $[105,106]$. Li et al. reported the effectiveness of miR-141-3p in EVs by comparing PCa with $\mathrm{BPH}$ patients and healthy controls [107]. They also found that the expression level was higher in metastatic PCa patients compared with localized patients, with an AUC of 0.8694 , sensitivity of $80 \%$ and specificity of $87.1 \%$ [107]. Due to the anatomical localization of the prostate, urine appears to be an ideal substrate to detect prostate carcinogenesis. Digital rectal examination (DRE) enhances the analytical performance of biomarker analysis in EVs, so a popular time for urine collection is after DRE [108]. Foj et al. recently revealed that among the most commonly deregulated miRNAs (miR-21-5p, miR-141-3p, miR-375, miR-214-3p and let-7c-5p) in PCa patients $[105,109,110]$, miR-21-5p, miR-375 and let$7 c-5 p$ are significantly upregulated in urinary EVs from PCa patients compared with healthy controls [111].
Huang et al. described prognostic biomarkers for patients with advanced-stage prostate cancer. They performed RNA sequencing to identify candidate miRNAs in the screening cohort $(\mathrm{n}=23)$ and confirmed that miR1290 and miR-375 in EVs are significantly associated with poor overall survival in castration-resistant prostate cancer (CRPC) patients $(n=100)$ [112].

The recent clinical introduction of novel antiandrogens and chemotherapeutics has extended the survival of patients with metastatic CRPC (mCRPC). However, the rates of de novo and acquired resistance are high, and thus a liquid biopsy that can rapidly, sensitively and robustly identify which patients will respond to the treatment is required [113]. The androgen receptor splice variant 7 (AR-V7) is associated with resistance to hormonal therapy in $\mathrm{mCRPC}$, and many researchers are focusing on the possibility of AR-V7 as a biomarker $[114,115]$. Although this report is not focused on miRNA, Del et al. demonstrated AR-V7 detected in RNA extracted from EVs could be a predictive biomarker of resistance to hormonal therapy [116].

\section{Breast cancer}

Breast cancer is the most common cancer in women in the United States, with an estimated 252,710 cases diagnosed in 2017 [89]. Traditional diagnostic methods, such as mammography, are effective but are known to have limited specificity and sensitivity. Although many studies have focused on the detection of circulating miRNAs in the serum or plasma of breast cancer patients, only a few studies to date have reported miRNAs in EVs from breast cancer patients. Eicheler et al. revealed that miR-101-3p and miR-372-3p in serum-derived EVs are significantly different between patients with breast cancer and healthy volunteers. They selected candidate miRNAs (miR101-3p, miR-372-3p and miR-373-3p) based on previous reports and quantified the expression of these miRNAs in serum-derived EVs from breast cancer patients $(n=50)$ and healthy volunteers $(\mathrm{n}=12)$ by qRT-PCR [117]. In another study, Hannafon et al. performed small RNA-seq and selected several miRNAs (miR-1246 miR-21-5p, miR122-5p and let-7a-5p) that were enriched in EVs derived from a breast cancer cell line compared with an epithelial cell line. They subsequently validated the expression of miRNAs in plasma-derived EVs and showed significantly higher levels of miR-1246 and miR-21-5p in breast cancer patients $(\mathrm{n}=16)$ compared with healthy controls $(n=16)$, each with AUCs of 0.69 and a combined AUC of 0.73 [118].

\section{Ovarian cancer}

Ovarian cancer ranked fifth in cancer deaths among women in 2017 and is the leading cause of death among 
gynecological malignancies in the United States [89]. EOC account for $90 \%$ of ovarian cancer, and its high mortality may be related to the asymptomatic status of affected individuals until the late stage of disease, and therefore is detected too late. Currently, CA125 is the most frequently used serum biomarker, but it is not sufficiently specific for the diagnosis of EOC at an early stage [119].

Meng et al. revealed that miR-373-3p, miR-200a-3p, miR-200b-3p and miR-200c-3p in EVs are useful to distinguish malignant and benign ovarian disease. They selected six candidate miRNAs (miR-141-3p, miR373-3p, miR-200a-3p, miR-200b-3p, miR-200c-3p and miR-429 from previous reports and evaluated them by qRT-PCR. They also evaluated the prognostic miRNAs in EVs and found that miR-200b-3p and miR-200c-3p were associated with an advanced FIGO stage and lymph node metastasis [120]. Ovarian cancer cells aggressively spread to the peritoneal cavity; therefore, ascetic fluid could be a useful and critical biomarker for ovarian cancer. Recently, Yokoi et al. found that highly metastatic ovarian cancer cells secrete EVs carrying MMP1 mRNA, and they revealed the potential utility of ascetic EVs as a risk indicator of peritoneal metastasis [69]. Although we could not find a clinical study to demonstrate the usefulness of miRNAs in ascites-derived EVs in ovarian cancer, as Tokuhisa et al. reported their effectiveness in gastric cancer [121], miRNAs in ascetic fluid hold great possibilities for predicting the status of ovarian cancer patients.

\section{Melanoma}

Melanoma is the most deadly form of skin cancer [89]. Localized melanoma is curable by surgical resection, and the 5 -year survival rate is $97 \%$. However, once the melanoma has spread to distant organs, it is refractory to existing therapies, and the 5-year survival rate declines to approximately $10 \%$ [122]. S100B, melanoma inhibitory activity (MIA) and lactate dehydrogenase (LDH) are the most widely used biomarkers for the metastatic developmental stage of melanoma, but they have very low sensitivity [123]. Thus, it is important to identify novel biomarkers for the management of melanoma patients.

Although several diagnostic EV biomarkers of melanoma have been reported [76, 123, 124], only two reports have been published concerning the effectiveness of miRNA in EVs as biomarkers. In 2014, Alegre et al. first assessed the diagnostic role of miRNAs in EVs derived from melanoma [125]. They selected miR-125b-5p, the circulating level of which had been assessed in previous reports of several kinds of cancers other than melanoma $[126,127]$. In their study, miR-125b-5p in serum EVs was significantly suppressed in advanced melanoma patients compared with healthy controls [125]. In 2015, Pfeffer et al. performed a microarray analysis using RNA prepared from plasma-derived EVs and validated the candidate miRNAs. They found that miR-17-5p, miR-19a-3p, miR-21-5p, miR-126-3p and miR-149-5p are expressed at higher levels in plasma-derived EVs from metastatic melanoma patients in comparison to normal control volunteers [128].

\section{Limitations for diagnostic applications}

As we have shown, a number of studies have focused on the clinical utility of miRNAs in EVs as tumor biomarkers (Table 2). Although some miRNAs in EVs are also highly expressed in serum or tissue, not all have provided consistent results, even in the same cancer types. One of the main explanation may be due to differences in cohort composition. To date, almost all studies have examined only a limited number of samples. miRNA levels correlate not only with disease condition but also, to some extent the characteristics of the patients, such as age, sex and ethnicity. Therefore, if the number of samples is limited, such a characteristic difference may cause inconsistent results between studies, and the lack of reference data to set up treatment thresholds. To overcome this problem, initial large-scale inter-laboratory studies should be performed.

In addition, several technical obstacles and scientific topics should also be considered. For effective biomarker analysis of EVs, a standardized method of EV collection is needed. As mentioned above, we currently cannot completely distinguish each type of EV. Ultracentrifugation is most common and conventional way to collect EVs, but it takes a large amount of time. Exo Quick is a fast and simple procedure, but it is a relatively crude isolation method with contaminating soluble proteins [9]. Density gradient-based isolation using sucrose or iodixanol (OptiPrep $^{\mathrm{TM}}$ ) can be used to isolate each EV fraction with greater purity than other methods. However, its application of the density gradient method in the clinical setting is questionable due to complications [129]. Furthermore, the differences in pre-analytical variables, such as sample-collecting and storage protocols are also important [130]. Therefore, the establishment of a standardized method that is simple, rapid, and has a high sensitivity of the sample purify is required.

Current miRNA measurement techniques should also be considered. Many studies have selected candidate miRNAs in EVs based on microarray results and validated them by qRT-PCR. qRT-PCR requires a suitable reference control gene that is challenging to identify. Some reports have used miR-16-5p as a housekeeping gene, which may serve as one standard [101, 105]. However, recent investigations of serum miRNA revealed a high variability in some diseases [131, 132]. In addition, 


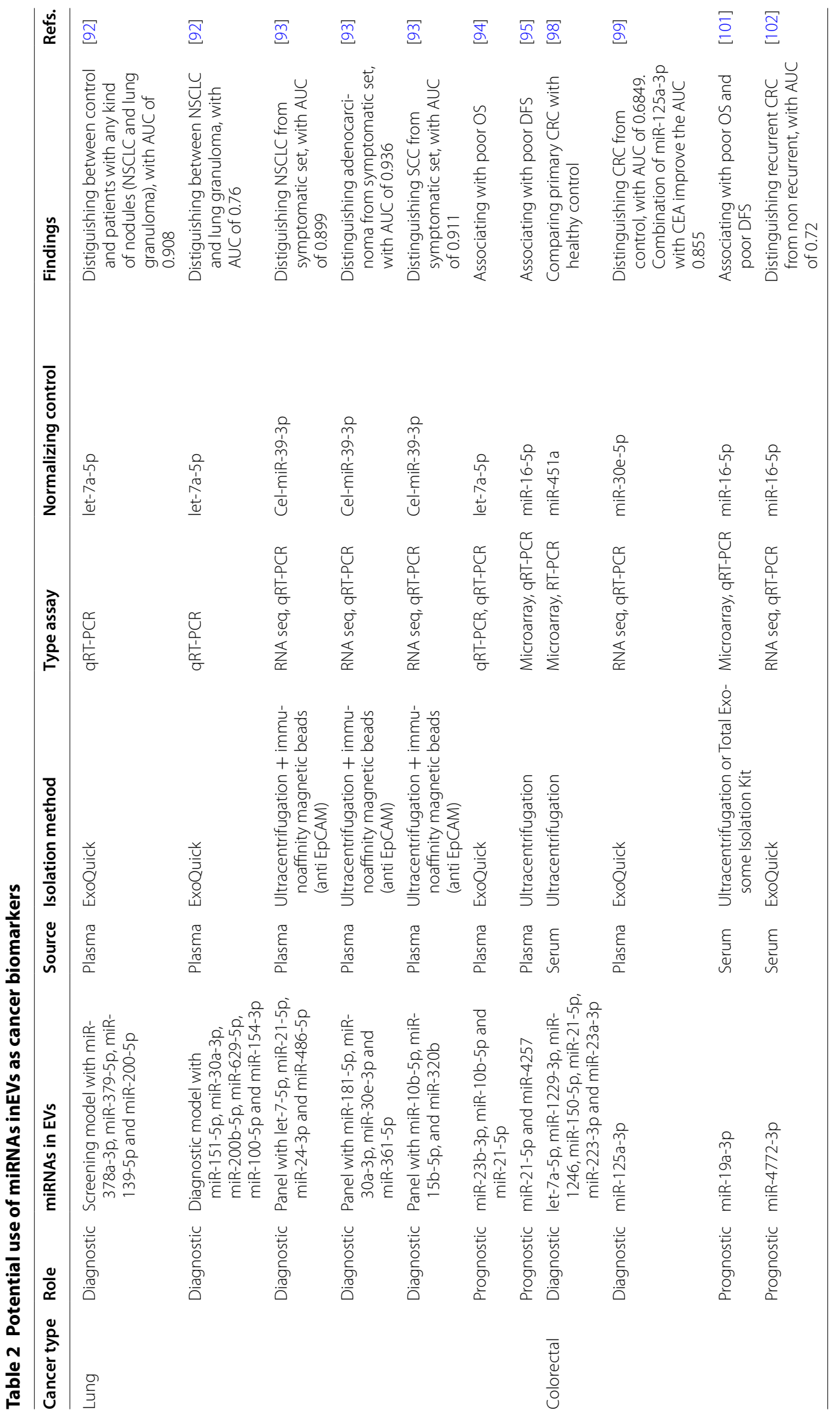




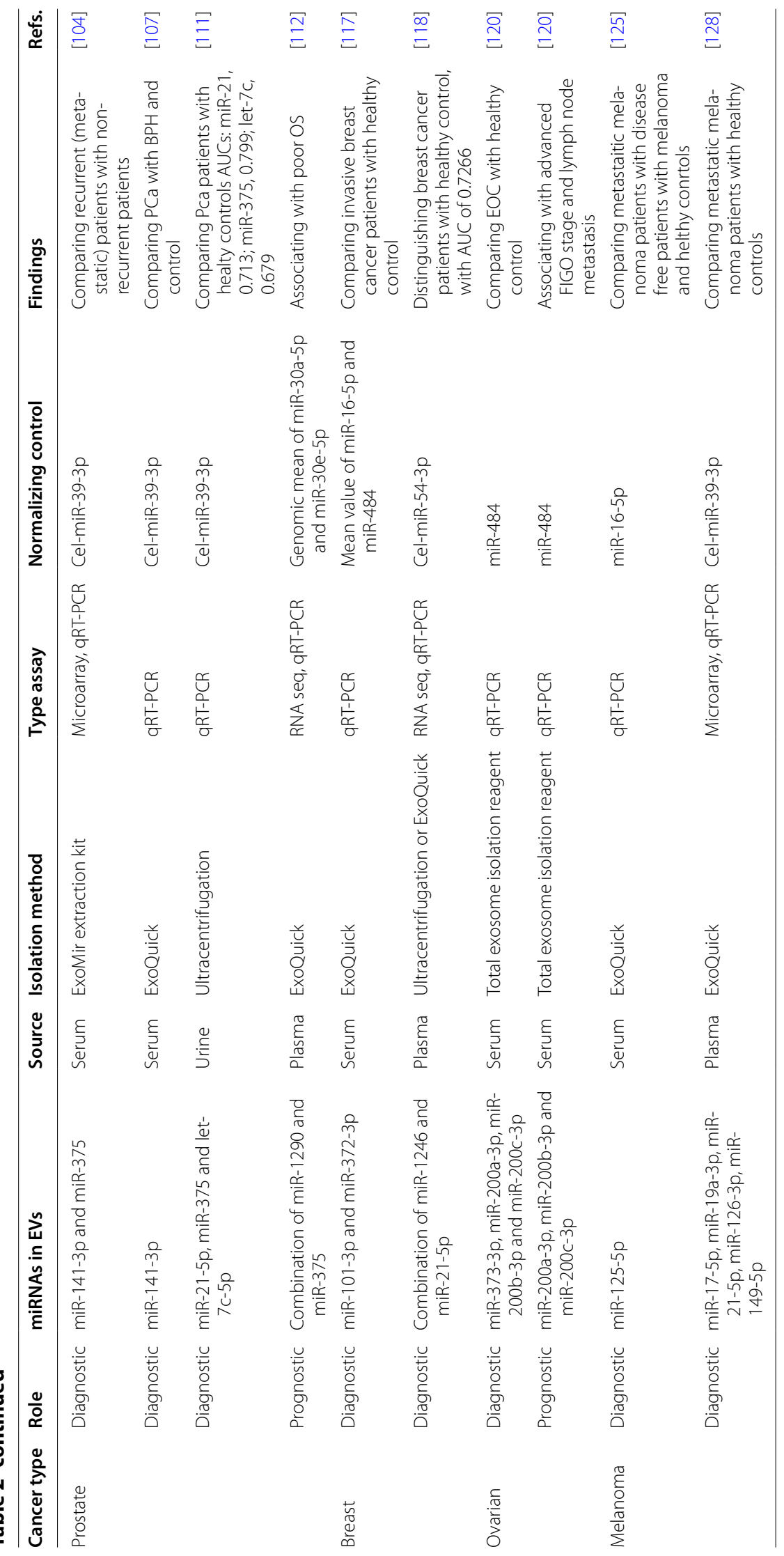


the spike-in external control, such as C. elegans miR$39-3 p$, is also a popular normalization control, but it is difficult to completely regulate the amount of this artificial external control added to different samples. The use of non-suitable reference genes may impede our understanding of the expression levels of miRNAs, and thus further cooperative studies are needed to identify proper housekeeping miRNAs.

A procedure to select candidate miRNAs is another scientific topic. In some reports, candidate miRNAs were selected by referencing previous findings for serum or plasma circulating miRNAs; however, miRNA profiles in EVs and circulating miRNA profiles were not completely consistent [133]. Microarray provides a genome-wide expression profile of miRNAs, facilitating the detection of a large number of aberrant miRNAs. However, probe development is challenging for some miRNAs [134]. Some recent reports selected candidate miRNAs by RNA-seq [93, 99, 102, 112, 118]. The advantage of using RNA-seq technology is its provision of a comprehensive analysis of the whole transcriptomes and distinction between miRNAs that differ by even 1 nucleotide. Compared with microarray technology, RNA-seq has the advantage of higher sensitivity and the ability to detect new miRNAs that have not been previously reported [135]. In addition, miRNAs show sequence heterogeneity at the $3^{\prime}$ and $5^{\prime}$ ends. This variation, which is called isomiR, is difficult to detect particularly using qPCRbased methods and is also exhibited in EVs [136]. Furthermore, several recent studies have focused on non-coding RNAs other than miRNAs in EVs $[59,137]$. Therefore, to detect these RNAs, the demand for highthroughput technologies such as RNA-seq will increase.

Recently, it was revealed that circulating miR-17-5p had been found at elevated level in all cancer types studied, and referred as early alarm signal for cancer [138]. Although miR-17-5p is not specific for a single type of cancer, combinations of miR-17-5p and cancer specific miRNAs in EVs might provide additional diagnostic power.

Thus, although miRNAs in EVs have great potential as cancer diagnostic or prognostic biomarkers, more investigations are required for effective implementation in the clinical setting.

\section{Conclusion}

In this review, we summarize current EV research to discuss the possibility of using the miRNAs in EVs in clinical applications. EVs play a pivotal role in the regulation of multiple systemic pathophysiological processes. Thus, targeting intercellular communication will provide a new therapeutic strategy. In addition, compared with biomarkers detected in conventional specimens such as serum, plasma or urine, EV biomarker provide comparable or higher specificity and sensitivity due to their stability. Furthermore, there has been intense interest in the potential of EVs as delivery vehicles, because EVs have some great characteristics, such as stability in the blood circulation, low side effect, and tropism to some organs [139]. Until now, several articles revealed that administration of exogenous EVs including miRNA or siRNA can be therapeutic strategies [140, 141].

Although further research and development are needed for implementation in the clinical setting, the clinical utility of EVs is promising. EV research is developing quite rapidly, and thus we may be able to use them as therapeutic tools in the near future.

We ardently hope that the advancements in EV research will contribute to the treatment of cancer.

\section{Abbreviations}

EV: extracellular vesicle; miRNA: microRNA; mRNA: messenger RNA; MVB: multivesicular body; ESCRT: endosomal-sorting complex required for transport; Hsp: heat shock protein; ISEV: international society of extracellular vesicles; $3^{\prime}$ UTR: $3^{\prime}$ untranslated region; SOCS5: suppressor of cytokine signaling 5; nSMase2: neutral sphingomyelinase 2; TIMP-1: tissue inhibitor of metalliprotease-1; ZO-1: zonula occludens-1; BBB: blood brain barrier; PDPK1: 3-phosphoinositide-dependent protein kinase-1; CAF: cancer-associated fibroblast; EMT: epithelial-mesenchymal transition; TNBC: triple negative breast cancer; ECM: extracellular matrix; MDSC: myeloid-derived-suppressor cell; TLR: toll-like receptor; TAM: tumor-associated macrophage; EOC: epithelial ovarian cancer; PD-L1: programmed death-1 ligand; CLL: chronic lymphocytic leukemia; MET: mesenchymal-to-epithelial transition; NSCLC: non-small-cell lung cancer; SOCS3: suppressor of cytokine signaling 3; BM-MSC: bone marrow mesenchymal stem cell; MARCKS: myristoylated alanine-rich C-kinase substrate; SCC: squamous cell carcinoma; AUC: area under the receiving operating characteristic curve; CRC: colorectal cancer; PCa: prostate cancer; PSA: prostate-specific antigen; $\mathrm{BPH}$ : benign prostatic hyperplasia; CRPC: castrationresistant prostate cancer; $\mathrm{mCRPC}$ : metastatic $C R P C ; A R-V 7$ : androgen receptor splice variant 7; LDH: lactate dehydrogenase; RNA-seq: RNA sequence; HSPG: heparan sulfate proteoglycan; GBM: glioblastoma.

\section{Authors' contributions}

FU wrote the manuscript with the help from NK, YY and SE provided helpful discussions. All authors edited and commented on the manuscript. The manuscript was finalized by TO and NK with the assistance of all the authors. All authors read and approved the final manuscript.

\section{Author details}

${ }^{1}$ Division of Molecular and Cellular Medicine, National Cancer Center Research Institute, 5-1-1 Tsukiji, Chuo-ku, Tokyo 104-0045, Japan. ${ }^{2}$ Department of Urology, Jikei University School of Medicine, 3-19-18 Nishi-Shimbashi, Minato-ku, Tokyo 105-8471, Japan.

\section{Acknowledgements}

We are grateful for Dr. Tsukasa Kadota for critical reading of the manuscript. We thank members of the Molecular and Cellular Medicine laboratory for critical discussion regarding this manuscript.

Competing interests

The authors declare that they have no competing interests.

Availability of data and materials

No applicable.

Consent for publication

No applicable. 


\section{Ethics approval and consent to participate}

No applicable.

\section{Funding}

This work was supported by the Practical Research for Innovative Cancer Control (17ck0106366h0001) from Japan Agency for Medical Research and Development, AMED.

\section{Publisher's Note}

Springer Nature remains neutral with regard to jurisdictional claims in published maps and institutional affiliations.

Received: 4 November 2017 Accepted: 3 December 2017

Published online: 13 December 2017

\section{References}

1. Denzer K, Kleijmeer MJ, Heijnen HF, Stoorvogel W, Geuze HJ (2000) Exosome: from internal vesicle of the multivesicular body to intercellular signaling device. J Cell Sci 113(Pt 19):3365-3374

2. Raposo G, Stoorvogel W (2013) Extracellular vesicles: exosomes, microvesicles, and friends. J Cell Biol 200(4):373-383

3. Yanez-Mo M, Siljander PR, Andreu Z, Zavec AB, Borras FE, Buzas El et al (2015) Biological properties of extracellular vesicles and their physiological functions. J Extracell Vesicles 4:27066

4. Cocucci E, Meldolesi J (2015) Ectosomes and exosomes: shedding the confusion between extracellular vesicles. Trends Cell Biol 25(6):364-372

5. Yoshioka Y, Konishi Y, Kosaka N, Katsuda T, Kato T, Ochiya T (2013) Comparative marker analysis of extracellular vesicles in different human cancer types. J Extracell Vesicles 2:20424

6. Simpson RJ, Lim JW, Moritz RL, Mathivanan S (2009) Exosomes: proteomic insights and diagnostic potential. Exp Rev Proteom 6(3):267-283

7. Cocucci E, Racchetti G, Meldolesi J (2009) Shedding microvesicles: artefacts no more. Trends Cell Biol 19(2):43-51

8. Muralidharan-Chari V, Clancy JW, Sedgwick A, D'Souza-Schorey C (2010) Microvesicles: mediators of extracellular communication during cancer progression. J Cell Sci 123(Pt 10):1603-1611

9. Van Deun J, Mestdagh P, Sormunen R, Cocquyt V, Vermaelen K, Vandesompele J et al (2014) The impact of disparate isolation methods for extracellular vesicles on downstream RNA profiling. J Extracell Vesicles 3:24858

10. Gould SJ, Raposo G (2013) As we wait: coping with an imperfect nomenclature for extracellular vesicles. J Extracell Vesicles 2:20389

11. Kosaka N, Yoshioka Y, Hagiwara K, Tominaga N, Katsuda T, Ochiya T (2013) Trash or treasure: extracellular microRNAs and cell-to-cell communication. Front Genet 4:173

12. Valadi H, Ekstrom K, Bossios A, Sjostrand M, Lee JJ, Lotvall JO (2007) Exosome-mediated transfer of mRNAs and microRNAs is a novel mechanism of genetic exchange between cells. Nat Cell Biol 9(6):654-659

13. Bartel DP (2009) MicroRNAs: target recognition and regulatory functions. Cell 136(2):215-233

14. Sayed D, Abdellatif M (2011) MicroRNAs in development and disease. Physiol Rev 91(3):827-887

15. Pegtel DM, Cosmopoulos K, Thorley-Lawson DA, van Eijndhoven MA Hopmans ES, Lindenberg JL et al (2010) Functional delivery of viral miRNAs via exosomes. Proc Natl Acad Sci USA 107(14):6328-6333

16. Kosaka N, Iguchi H, Yoshioka Y, Hagiwara K, Takeshita F, Ochiya T (2012) Competitive interactions of cancer cells and normal cells via secretory microRNAs. J Biol Chem 287(2):1397-1405

17. Zhang Y, Liu D, Chen X, Li J, Li L, Bian Z et al (2010) Secreted monocytic miR-150 enhances targeted endothelial cell migration. Mol Cell 39(1):133-144

18. Kosaka N, Yoshioka Y, Fujita Y, Ochiya T (2016) Versatile roles of extracellular vesicles in cancer. J Clin Investig 126(4):1163-1172

19. Fujita Y, Yoshioka Y, Ochiya T (2016) Extracellular vesicle transfer of cancer pathogenic components. Cancer Sci 107(4):385-390

20. Liao D, Johnson RS (2007) Hypoxia: a key regulator of angiogenesis in cancer. Cancer Metastasis Rev 26(2):281-290
21. Carmeliet P, Jain RK (2000) Angiogenesis in cancer and other diseases. Nature 407(6801):249-257

22. Folkman J (2002) Role of angiogenesis in tumor growth and metastasis. Semin Oncol 29(6 Suppl 16):15-18

23. Welti J, Loges S, Dimmeler S, Carmeliet P (2013) Recent molecular discoveries in angiogenesis and antiangiogenic therapies in cancer. J Clin Investig 123(8):3190-3200

24. Zhuang G, Wu X, Jiang Z, Kasman I, Yao J, Guan Y et al (2012) Tumoursecreted miR-9 promotes endothelial cell migration and angiogenesis by activating the JAK-STAT pathway. EMBO J 31(17):3513-3523

25. Kosaka N, Iguchi H, Hagiwara K, Yoshioka Y, Takeshita F, Ochiya T (2013) Neutral sphingomyelinase 2 (nSMase2)-dependent exosomal transfer of angiogenic microRNAs regulate cancer cell metastasis. J Biol Chem 288(15):10849-10859

26. Cui H, Seubert B, Stahl E, Dietz H, Reuning U, Moreno-Leon L et al (2015) Tissue inhibitor of metalloproteinases-1 induces a pro-tumourigenic increase of miR-210 in lung adenocarcinoma cells and their exosomes. Oncogene 34(28):3640-3650

27. Hsu YL, Hung JY, Chang WA, Lin YS, Pan YC, Tsai PH et al (2017) Hypoxic lung cancer-secreted exosomal miR-23a increased angiogenesis and vascular permeability by targeting prolyl hydroxylase and tight junction protein ZO-1. Oncogene 36(34):4929-4942

28. Chan YC, Banerjee J, Choi SY, Sen CK (2012) miR-210: the master hypoxamir. Microcirculation (New York, NY: 1994) 19(3):215-223

29. Fasanaro P, D'Alessandra Y, Di Stefano V, Melchionna R, Romani S, Pompilio G et al (2008) MicroRNA-210 modulates endothelial cell response to hypoxia and inhibits the receptor tyrosine kinase ligand Ephrin-A3. J Biol Chem 283(23):15878-15883

30. Rodriguez PL, Jiang S, Fu Y, Avraham S, Avraham HK (2014) The proinflammatory peptide substance $P$ promotes blood-brain barrier breaching by breast cancer cells through changes in microvascular endothelial cell tight junctions. Int J Cancer 134(5):1034-1044

31. Arshad F, Wang L, Sy C, Avraham S, Avraham HK (2010) Blood-brain barrier integrity and breast cancer metastasis to the brain. Pathol Res Int 2011:920509

32. Zhou W, Fong MY, Min Y, Somlo G, Liu L, Palomares MR et al (2014) Cancer-secreted miR-105 destroys vascular endothelial barriers to promote metastasis. Cancer Cell 25(4):501-515

33. Tominaga N, Kosaka N, Ono M, Katsuda T, Yoshioka Y, Tamura K et al (2015) Brain metastatic cancer cells release microRNA-181c-containing extracellular vesicles capable of destructing blood-brain barrier. Nat Commun 6:6716

34. Gotink KJ, Verheul HM (2010) Anti-angiogenic tyrosine kinase inhibitors: what is their mechanism of action? Angiogenesis 13(1):1-14

35. Lu H, Jiang Z (2017) Advances in antiangiogenic treatment of small-cell lung cancer. OncoTargets Ther 10:353-359

36. Aalders KC, Tryfonidis K, Senkus E, Cardoso F (2017) Anti-angiogenic treatment in breast cancer: facts, successes, failures and future perspectives. Cancer Treat Rev 53.98-110

37. Bremnes RM, Donnem T, Al-Saad S, Al-Shibli K, Andersen S, Sirera R et al (2011) The role of tumor stroma in cancer progression and prognosis: emphasis on carcinoma-associated fibroblasts and non-small cell lung cancer. J Thorac Oncol 6(1):209-217

38. Guido C, Whitaker-Menezes D, Capparelli C, Balliet R, Lin Z, Pestell RG et al (2012) Metabolic reprogramming of cancer-associated fibroblasts by TGF-beta drives tumor growth: connecting TGF-beta signaling with "Warburg-like" cancer metabolism and L-lactate production. Cell Cycle (Georgetown, Tex) 11(16):3019-3035

39. Franco OE, Jiang M, Strand DW, Peacock J, Fernandez S, Jackson RS 2nd et al (2011) Altered TGF-beta signaling in a subpopulation of human stromal cells promotes prostatic carcinogenesis. Cancer Res 71(4):1272-1281

40. Pang W, Su J, Wang Y, Feng H, Dai X, Yuan Y et al (2015) Pancreatic cancer-secreted miR-155 implicates in the conversion from normal fibroblasts to cancer-associated fibroblasts. Cancer Sci 106(10):1362-1369

41. Au Yeung CL, Co NN, Tsuruga T, Yeung TL, Kwan SY, Leung CS et al (2016) Exosomal transfer of stroma-derived miR21 confers paclitaxel resistance in ovarian cancer cells through targeting APAF1. Nat Commun 7:11150

42. Donnarumma E, Fiore D, Nappa M, Roscigno G, Adamo A, laboni M et al (2017) Cancer-associated fibroblasts release exosomal microRNAs 
that dictate an aggressive phenotype in breast cancer. Oncotarget 8(12):19592-19608

43. Baroni S, Romero-Cordoba S, Plantamura I, Dugo M, D'lppolito E, Cataldo A et al (2016) Exosome-mediated delivery of miR-9 induces cancer-associated fibroblast-like properties in human breast fibroblasts. Cell Death Dis 7(7):e2312

44. Rana S, Malinowska K, Zoller M (2013) Exosomal tumor microRNA modulates premetastatic organ cells. Neoplasia (New York, NY) 15(3):281-295

45. Fong MY, Zhou W, Liu L, Alontaga AY, Chandra M, Ashby J et al (2015) Breast-cancer-secreted miR-122 reprograms glucose metabolism in premetastatic niche to promote metastasis. Nat Cell Biol 17(2):183-194

46. Peinado H, Zhang H, Matei IR, Costa-Silva B, Hoshino A, Rodrigues $\mathrm{G}$ et al (2017) Pre-metastatic niches: organ-specific homes for metastases. Nat Rev Cancer 17(5):302-317

47. Hanahan D, Weinberg RA (2011) Hallmarks of cancer: the next generation. Cell 144(5):646-674

48. Zitvogel L, Regnault A, Lozier A, Wolfers J, Flament C, Tenza D et al (1998) Eradication of established murine tumors using a novel cell-free vaccine: dendritic cell-derived exosomes. Nat Med 4(5):594-600

49. Wolfers J, Lozier A, Raposo G, Regnault A, Thery C, Masurier C et al (2001) Tumor-derived exosomes are a source of shared tumor rejection antigens for CTL cross-priming. Nat Med 7(3):297-303

50. Kim JW, Wieckowski E, Taylor DD, Reichert TE, Watkins S, Whiteside TL (2005) Fas ligand-positive membranous vesicles isolated from sera of patients with oral cancer induce apoptosis of activated T lymphocytes. Clin Cancer Res 11(3):1010-1020

51. Talmadge JE, Gabrilovich DI (2013) History of myeloid-derived suppressor cells. Nat Rev Cancer 13(10):739-752

52. Chalmin F, Ladoire S, Mignot G, Vincent J, Bruchard M, Remy-Martin JP et al (2010) Membrane-associated Hsp72 from tumor-derived exosomes mediates STAT3-dependent immunosuppressive function of mouse and human myeloid-derived suppressor cells. J Clin Investig 120(2):457-471

53. Fabbri M, Paone A, Calore F, Galli R, Gaudio E, Santhanam R et al (2012) MicroRNAs bind to toll-like receptors to induce prometastatic inflammatory response. Proc Natl Acad Sci USA 109(31):E2110-E2116

54. Ying $X$, Wu Q, Wu X, Zhu Q, Wang X, Jiang L et al (2016) Epithelial ovarian cancer-secreted exosomal miR-222-3p induces polarization of tumor-associated macrophages. Oncotarget 7(28):43076-43087

55. Okazaki T, Honjo T (2007) PD-1 and PD-1 ligands: from discovery to clinical application. Int Immunol 19(7):813-824

56. Fujita Y, Yagishita S, Hagiwara K, Yoshioka Y, Kosaka N, Takeshita F et al (2015) The clinical relevance of the miR-197/CKS1B/STAT3-mediated PD-L1 network in chemoresistant non-small-cell lung cancer. Mol Ther 23(4):717-727

57. Chen L, Gibbons DL, Goswami S, Cortez MA, Ahn YH, Byers LA et al (2014) Metastasis is regulated via microRNA-200/ZEB1 axis control of tumour cell PD-L1 expression and intratumoral immunosuppression. Nat Commun 5:5241

58. Kataoka K, Shiraishi Y, Takeda Y, Sakata S, Matsumoto M, Nagano S et al (2016) Aberrant PD-L1 expression through 3'-UTR disruption in multiple cancers. Nature 534(7607):402-406

59. Haderk F, Schulz R, Iskar M, Cid LL, Worst T, Willmund KV et al (2017) Tumor-derived exosomes modulate PD-L1 expression in monocytes. Sci Immunol 2(13):eaah5509

60. Moreno E (2008) Is cell competition relevant to cancer? Nat Rev Cancer 8(2):141-147

61. Le MT, Hamar P, Guo C, Basar E, Perdigao-Henriques R, Balaj L et al (2014) miR-200-containing extracellular vesicles promote breast cancer cell metastasis. J Clin Investig 124(12):5109-5128

62. Singh R, Pochampally R, Watabe K, Lu Z, Mo YY (2014) Exosome-mediated transfer of miR-10b promotes cell invasion in breast cancer. Mol Cancer 13:256

63. Holohan C, Van Schaeybroeck S, Longley DB, Johnston PG (2013) Cancer drug resistance: an evolving paradigm. Nat Rev Cancer 13(10):714-726

64. Chen WX, Liu XM, Lv MM, Chen L, Zhao JH, Zhong SL et al (2014) Exosomes from drug-resistant breast cancer cells transmit chemoresistance by a horizontal transfer of microRNAs. PLoS ONE 9(4):e95240
65. Wei F, Ma C, Zhou T, Dong X, Luo Q, Geng L et al (2017) Exosomes derived from gemcitabine-resistant cells transfer malignant phenotypic traits via delivery of miRNA-222-3p. Mol Cancer 16(1):132

66. Challagundla KB, Wise PM, Neviani P, Chava H, Murtadha M, Xu T et al (2015) Exosome-mediated transfer of microRNAs within the tumor microenvironment and neuroblastoma resistance to chemotherapy. J Nat Cancer Inst 107(7):djv135

67. Kurtz JM, Spitalier JM, Amalric R (1983) Late breast recurrence after lumpectomy and irradiation. Int J Radiat Oncol Biol Phys 9(8):1191-1194

68. Ono M, Kosaka N, Tominaga N, Yoshioka Y, Takeshita F, Takahashi RU et al (2014) Exosomes from bone marrow mesenchymal stem cells contain a microRNA that promotes dormancy in metastatic breast cancer cells. Sci Signal 7(332):ra63

69. Yokoi A, Yoshioka Y, Yamamoto Y, Ishikawa M, Ikeda SI, Kato T et al (2017) Malignant extracellular vesicles carrying MMP1 mRNA facilitate peritoneal dissemination in ovarian cancer. Nat Commun 8:14470

70. Ostrowski M, Carmo NB, Krumeich S, Fanget I, Raposo G, Savina A et al (2010) Rab27a and Rab27b control different steps of the exosome secretion pathway. Nat Cell Biol 12(1):19-30

71. Baietti MF, Zhang Z, Mortier E, Melchior A, Degeest G, Geeraerts A et al (2012) Syndecan-syntenin-ALIX regulates the biogenesis of exosomes. Nat Cell Biol 14(7):677-685

72. Yuyama K, Sun H, Mitsutake S, Igarashi Y (2012) Sphingolipid-modulated exosome secretion promotes clearance of amyloid-beta by microglia. J Biol Chem 287(14):10977-10989

73. Phuyal S, Hessvik NP, Skotland T, Sandvig K, Llorente A (2014) Regulation of exosome release by glycosphingolipids and flotillins. FEBS J 281(9):2214-2227

74. Marleau AM, Chen CS, Joyce JA, Tullis RH (2012) Exosome removal as a therapeutic adjuvant in cancer. J Transl Med 10:134

75. Ciravolo V, Huber V, Ghedini GC, Venturelli E, Bianchi F, Campiglio M et al (2012) Potential role of HER2-overexpressing exosomes in countering trastuzumab-based therapy. J Cell Physiol 227(2):658-667

76. Peinado H, Aleckovic M, Lavotshkin S, Matei I, Costa-Silva B, MorenoBueno G et al (2012) Melanoma exosomes educate bone marrow progenitor cells toward a pro-metastatic phenotype through MET. Nat Med 18(6):883-891

77. Nishida-Aoki N, Tominaga N, Takeshita F, Sonoda H, Yoshioka Y, Ochiya T (2017) Disruption of circulating extracellular vesicles as a novel therapeutic strategy against cancer metastasis. Mol Ther 25(1):181-191

78. Christianson HC, Svensson KJ, van Kuppevelt TH, Li JP, Belting M (2013) Cancer cell exosomes depend on cell-surface heparan sulfate proteoglycans for their internalization and functional activity. Proc Natl Acad Sci USA 110(43):17380-17385

79. Mulcahy LA, Pink RC, Carter DR (2014) Routes and mechanisms of extracellular vesicle uptake. J Extracell Vesicles. 3:24641

80. Svensson KJ, Christianson HC, Wittrup A, Bourseau-Guilmain E, Lindqvist E, Svensson LM et al (2013) Exosome uptake depends on ERK1/2-heat shock protein 27 signaling and lipid raft-mediated endocytosis negatively regulated by caveolin-1. J Biol Chem 288(24):17713-17724

81. Kawamoto T, Ohga N, Akiyama K, Hirata N, Kitahara S, Maishi N et al (2012) Tumor-derived microvesicles induce proangiogenic phenotype in endothelial cells via endocytosis. PLoS ONE 7(3):e34045

82. Kowal J, Arras G, Colombo M, Jouve M, Morath JP, Primdal-Bengtson B et al (2016) Proteomic comparison defines novel markers to characterize heterogeneous populations of extracellular vesicle subtypes. Proc Natl Acad Sci USA 113(8):E968-E977

83. Tkach M, Kowal J, Zucchetti AE, Enserink L, Jouve M, Lankar D et al (2017) Qualitative differences in T-cell activation by dendritic cellderived extracellular vesicle subtypes. EMBO J 36(20):3012-3028

84. Skog J, Wurdinger T, van Rijn S, Meijer DH, Gainche L, Sena-Esteves M et al (2008) Glioblastoma microvesicles transport RNA and proteins that promote tumour growth and provide diagnostic biomarkers. Nat Cell Biol 10(12):1470-1476

85. Caby MP, Lankar D, Vincendeau-Scherrer C, Raposo G, Bonnerot C (2005) Exosomal-like vesicles are present in human blood plasma. Int Immunol 17(7):879-887 
86. Pisitkun T, Shen RF, Knepper MA (2004) Identification and proteomic profiling of exosomes in human urine. Proc Natl Acad Sci USA 101(36):13368-13373

87. Palanisamy V, Sharma S, Deshpande A, Zhou H, Gimzewski J, Wong DT (2010) Nanostructural and transcriptomic analyses of human saliva derived exosomes. PLoS ONE 5(1):e8577

88. Poliakov A, Spilman M, Dokland T, Amling CL, Mobley JA (2009) Structural heterogeneity and protein composition of exosome-like vesicles (prostasomes) in human semen. Prostate 69(2):159-167

89. Siegel RL, Miller KD, Jemal A (2017) Cancer statistics, 2017. CA Cancer J Clin 67(1):7-30

90. Chen Z, Fillmore CM, Hammerman PS, Kim CF, Wong KK (2014) Nonsmall-cell lung cancers: a heterogeneous set of diseases. Nat Rev Cancer 14(8):535-546

91. Aberle DR, Adams AM, Berg CD, Black WC, Clapp JD, Fagerstrom RM et al (2011) Reduced lung-cancer mortality with low-dose computed tomographic screening. N Engl J Med 365(5):395-409

92. Cazzoli R, Buttitta F, Di Nicola M, Malatesta S, Marchetti A, Rom WN et al (2013) microRNAs derived from circulating exosomes as noninvasive biomarkers for screening and diagnosing lung cancer. J Thorac Oncol 8(9):1156-1162

93. Jin X, Chen Y, Chen H, Fei S, Chen D, Cai X et al (2017) Evaluation of tumor-derived exosomal miRNA as potential diagnostic biomarkers for early-stage non-small cell lung cancer using next-generation sequencing. Clin Cancer Res. 23(17):5311-5319

94. Liu Q, Yu Z, Yuan S, Xie W, Li C, Hu Z et al (2017) Circulating exosomal. microRNAs as prognostic biomarkers for non-small-cell lung cancer. Oncotarget 8(8):13048-13058

95. Dejima $\mathrm{H}$, linuma $\mathrm{H}$, Kanaoka R, Matsutani N, Kawamura M (2017) Exosomal microRNA in plasma as a non-invasive biomarker for the recurrence of non-small cell lung cancer. Oncol Lett 13(3):1256-1263

96. Miller KD, Siegel RL, Lin CC, Mariotto AB, Kramer JL, Rowland JH et al (2016) Cancer treatment and survivorship statistics, 2016. CA Cancer J Clin 66(4):271-289

97. Locker GY, Hamilton S, Harris J, Jessup JM, Kemeny N, Macdonald JS et al (2006) ASCO 2006 update of recommendations for the use of tumor markers in gastrointestinal cancer. J Clin Oncol 24(33):5313-5327

98. Ogata-Kawata H, Izumiya M, Kurioka D, Honma Y, Yamada Y, Furuta K et al (2014) Circulating exosomal microRNAs as biomarkers of colon cancer. PLoS ONE 9(4):e92921

99. Wang J, Yan F, Zhao Q, Zhan F, Wang R, Wang L et al (2017) Circulating exosomal miR-125a-3p as a novel biomarker for early-stage colon cancer. Sci Rep 7(1):4150

100. Akiyoshi T, Kobunai T, Watanabe T (2012) Recent approaches to identifying biomarkers for high-risk stage II colon cancer. Surg Today 42(11):1037-1045

101. Matsumura T, Sugimachi K, linuma H, Takahashi Y, Kurashige J, Sawada $\mathrm{G}$ et al (2015) Exosomal microRNA in serum is a novel biomarker of recurrence in human colorectal cancer. Br J Cancer 113(2):275-281

102. Liu C, Eng C, Shen J, Lu Y, Takata Y, Mehdizadeh A et al (2016) Serum exosomal miR-4772-3p is a predictor of tumor recurrence in stage II and III colon cancer. Oncotarget 7(46):76250-76260

103. Mazzucchelli R, Colanzi P, Pomante R, Muzzonigro G, Montironi R (2000) Prostate tissue and serum markers. Adv Clin Pathol 4(3):111-120

104. Bryant RJ, Pawlowski T, Catto JW, Marsden G, Vessella RL, Rhees B et al (2012) Changes in circulating microRNA levels associated with prostate cancer. Br J Cancer 106(4):768-774

105. Mitchell PS, Parkin RK, Kroh EM, Fritz BR, Wyman SK, Pogosova-Agadjanyan EL et al (2008) Circulating microRNAs as stable blood-based markers for cancer detection. Proc Natl Acad Sci USA 105(30):10513-10518

106. Yaman Agaoglu F, Kovancilar M, Dizdar Y, Darendeliler E, Holdenrieder S, Dalay N et al (2011) Investigation of miR-21, miR-141, and miR-221 in blood circulation of patients with prostate cancer. Tumour Biol 32(3):583-588

107. Li Z, Ma YY, Wang J, Zeng XF, Li R, Kang W et al (2016) Exosomal microRNA-141 is upregulated in the serum of prostate cancer patients. Onco Targets Ther 9:139-148

108. Dijkstra S, Birker IL, Smit FP, Leyten GH, de Reijke TM, van Oort IM et al (2014) Prostate cancer biomarker profiles in urinary sediments and exosomes. J Urol 191(4):1132-1138
109. Fabris $L$, Ceder $Y$, Chinnaiyan AM, Jenster GW, Sorensen KD, Tomlins $S$ et al (2016) The potential of MicroRNAs as prostate cancer biomarkers. Eur Urol 70(2):312-322

110. Porkka KP, Pfeiffer MJ, Waltering KK, Vessella RL, Tammela TL, Visakorpi $T$ (2007) MicroRNA expression profiling in prostate cancer. Cancer Res 67(13):6130-6135

111. Foj L, Ferrer F, Serra M, Arevalo A, Gavagnach M, Gimenez N et al (2017) Exosomal and non-exosomal urinary mirnas in prostate cancer detection and prognosis. Prostate 77(6):573-583

112. Huang $X$, Yuan T, Liang M, Du M, Xia S, Dittmar R et al (2015) Exosomal miR-1290 and miR-375 as prognostic markers in castration-resistant prostate cancer. Eur Urol 67(1):33-41

113. Fletcher C (2017) AR-v7 liquid biopsy for treatment stratification in prostate cancer: how close are we? Curr Opin Urol 27(5):500-509

114. Antonarakis ES, Lu C, Wang H, Luber B, Nakazawa M, Roeser JC et al (2014) AR-V7 and resistance to enzalutamide and abiraterone in prostate cancer. N Engl J Med 371(11):1028-1038

115. Scher HI, Lu D, Schreiber NA, Louw J, Graf RP, Vargas HA et al (2016) Association of AR-V7 on circulating tumor cells as a treatment-specific biomarker with outcomes and survival in castration-resistant prostate cancer. JAMA Oncol 2(11):1441-1449

116. Del Re M, Biasco E, Crucitta S, Derosa L, Rofi E, Orlandini C et al (2017) The detection of androgen receptor splice variant 7 in plasma-derived exosomal RNA strongly predicts resistance to hormonal therapy in metastatic prostate cancer patients. Eur Urol 71 (4):680-687

117. Eichelser C, Stuckrath I, Muller V, Milde-Langosch K, Wikman H, Pantel K et al (2014) Increased serum levels of circulating exosomal microRNA-373 in receptor-negative breast cancer patients. Oncotarget 5(20):9650-9663

118. Hannafon BN, Trigoso YD, Calloway CL, Zhao YD, Lum DH, Welm AL et al (2016) Plasma exosome microRNAs are indicative of breast cancer. BCR 18(1):90

119. Meinhold-Heerlein I, Hauptmann S (2014) The heterogeneity of ovarian cancer. Arch Gynecol Obstet 289(2):237-239

120. Meng X, Muller V, Milde-Langosch K, Trillsch F, Pantel K, Schwarzenbach $H$ (2016) Diagnostic and prognostic relevance of circulating exosomal miR-373, miR-200a, miR-200b and miR-200c in patients with epithelial ovarian cancer. Oncotarget 7(13):16923-16935

121. Tokuhisa M, Ichikawa Y, Kosaka N, Ochiya T, Yashiro M, Hirakawa K et al (2015) Exosomal miRNAs from peritoneum lavage fluid as potential prognostic biomarkers of peritoneal metastasis in gastric cancer. PLoS ONE 10(7):e0130472

122. Balch CM, Gershenwald JE, Soong SJ, Thompson JF, Atkins MB, Byrd DR et al (2009) Final version of 2009 AJCC melanoma staging and classification. J Clin Oncol 27(36):6199-6206

123. Alegre E, Zubiri L, Perez-Gracia JL, Gonzalez-Cao M, Soria L, MartinAlgarra S et al (2016) Circulating melanoma exosomes as diagnostic and prognosis biomarkers. Clin Chim Acta 454:28-32

124. Logozzi M, De Milito A, Lugini L, Borghi M, Calabro L, Spada M et al (2009) High levels of exosomes expressing CD63 and caveolin-1 in plasma of melanoma patients. PLoS ONE 4(4):e5219

125. Alegre E, Sanmamed MF, Rodriguez C, Carranza O, Martin-Algarra S, Gonzalez A (2014) Study of circulating microRNA-125b levels in serum exosomes in advanced melanoma. Arch Pathol Lab Med 138(6):828-832

126. Wang H, Tan G, Dong L, Cheng L, Li K, Wang Z et al (2012) Circulating MiR-125b as a marker predicting chemoresistance in breast cancer. PLOS ONE 7(4):e34210

127. Yuxia M, Zhennan T, Wei Z (2012) Circulating miR-125b is a novel biomarker for screening non-small-cell lung cancer and predicts poor prognosis. J Cancer Res Clin Oncol 138(12):2045-2050

128. Pfeffer SR, Grossmann KF, Cassidy PB, Yang CH, Fan M, Kopelovich L et al (2015) Detection of exosomal miRNAs in the plasma of melanoma patients. J Clin Med 4(12):2012-2027

129. Thind A, Wilson C (2016) Exosomal miRNAs as cancer biomarkers and therapeutic targets. J Extracell Vesicles. 5:31292

130. McDonald JS, Milosevic D, Reddi HV, Grebe SK, Algeciras-Schimnich A (2011) Analysis of circulating microRNA: preanalytical and analytical challenges. Clin Chem 57(6):833-840 
131. Watahiki A, Macfarlane RJ, Gleave ME, Crea F, Wang Y, Helgason CD et al (2013) Plasma miRNAs as biomarkers to identify patients with castration-resistant metastatic prostate cancer. Int J Mol Sci 14(4):7757-7770

132. Filkova M, Aradi B, Senolt L, Ospelt C, Vettori S, Mann H et al (2014) Association of circulating miR-223 and miR-16 with disease activity in patients with early rheumatoid arthritis. Ann Rheum Dis 73(10):1898-1904

133. Cheng L, Sharples RA, Scicluna BJ, Hill AF (2014) Exosomes provide a protective and enriched source of miRNA for biomarker profiling compared to intracellular and cell-free blood. J Extracell Vesicles 3:23743

134. Huang X, Yuan T, Tschannen M, Sun Z, Jacob H, Du M et al (2013) Characterization of human plasma-derived exosomal RNAs by deep sequencing. BMC Genom 14:319

135. Berezikov E, Cuppen E, Plasterk RH (2006) Approaches to microRNA discovery. Nat Genet 38(Suppl):S2-S7

136. Koppers-Lalic D, Hackenberg M, de Menezes R, Misovic B, Wachalska M, Geldof A et al (2016) Noninvasive prostate cancer detection by measuring miRNA variants (isomiRs) in urine extracellular vesicles. Oncotarget 7(16):22566-22578

137. Berrondo C, Flax J, Kucherov V, Siebert A, Osinski T, Rosenberg A et al (2016) Expression of the long non-coding RNA HOTAIR correlates with disease progression in bladder cancer and is contained in bladder cancer patient urinary exosomes. PLOS ONE 11(1):e0147236

138. Bobbili MR, Mader RM, Grillari J, Dellago H (2017) OncomiR-17-5p: alarm signal in cancer? Oncotarget 8(41):71206-71222

139. Ela S, Mager I, Breakefield XO, Wood MJ (2013) Extracellular vesicles: biology and emerging therapeutic opportunities. Nat Rev Drug Discov 12(5):347-357

140. Ohno S, Takanashi M, Sudo K, Ueda S, Ishikawa A, Matsuyama N et al (2013) Systemically injected exosomes targeted to EGFR deliver antitumor microRNA to breast cancer cells. Mol Ther 21(1):185-191

141. Alvarez-Erviti L, Seow Y, Yin H, Betts C, Lakhal S, Wood MJ (2011) Delivery of siRNA to the mouse brain by systemic injection of targeted exosomes. Nat Biotechnol 29(4):341-345

\section{Submit your manuscript to a SpringerOpen ${ }^{\circ}$ journal and benefit from:}

- Convenient online submission

- Rigorous peer review

- Open access: articles freely available online

- High visibility within the field

- Retaining the copyright to your article

Submit your next manuscript at springeropen.com 